NBER WORKING PAPER SERIES

DO LOTTERY PAYMENTS INDUCE SAVINGS BEHAVIOR:
EVIDENCE FROM THE LAB

\author{
Emel Filiz-Ozbay \\ Jonathan Guryan \\ Kyle Hyndman \\ Melissa Schettini Kearney \\ Erkut Y. Ozbay \\ Working Paper 19130 \\ http://www.nber.org/papers/w19130
}

\author{
NATIONAL BUREAU OF ECONOMIC RESEARCH \\ 1050 Massachusetts Avenue \\ Cambridge, MA 02138 \\ June 2013
}

We thank the University of Maryland, Department of Economics for its generous financial support for this research. We thank seminar participants at Penn State University (Smeal College of Business) and University College London, conference participants at the 2013 RAND Behavioral Finance Forum and the Decision Theory Conference at ITAM, as well as Matthew Embrey, Philippe Jehiel, Anthony Kwasnica and Antoine Terracol for helpful discussions. Kristian López-Vargas programmed the experiment in z-Tree and also provided excellent assistance during the experimental sessions. The views expressed herein are those of the authors and do not necessarily reflect the views of the National Bureau of Economic Research.

NBER working papers are circulated for discussion and comment purposes. They have not been peerreviewed or been subject to the review by the NBER Board of Directors that accompanies official NBER publications.

(C) 2013 by Emel Filiz-Ozbay, Jonathan Guryan, Kyle Hyndman, Melissa Schettini Kearney, and Erkut Y. Ozbay. All rights reserved. Short sections of text, not to exceed two paragraphs, may be quoted without explicit permission provided that full credit, including $\odot$ notice, is given to the source. 
Do Lottery Payments Induce Savings Behavior: Evidence from the Lab

Emel Filiz-Ozbay, Jonathan Guryan, Kyle Hyndman, Melissa Schettini Kearney, and Erkut

Y. Ozbay

NBER Working Paper No. 19130

June 2013

JEL No. D03,D14,D81,G11

\section{ABSTRACT}

This paper presents the results of a laboratory experiment designed to investigate whether the option of a Prize Linked Savings (PLS) product alters the likelihood that subjects choose to delay payment. By comparing PLS and standard savings products in a controlled way, we find strong evidence that a PLS payment option leads to greater rates of payment deferral than does a straightforward interest payment option of the same expected value. The appeal of the PLS option is strongest among men, self-reported lottery players, and subjects with low bank account balances. We use the results of our experiment to structurally estimate the parameters of the decision problem governing time preference, risk aversion, and probability weighting. We employ the parameter estimates in a series of policy simulations that compare the relative effectiveness of PLS products as compared to standard savings products.

Emel Filiz-Ozbay

Department of Economics

University of Maryland

3114 Tydings Hall

College Park, MD 20742

filizozbay@econ.umd.edu

Jonathan Guryan

Northwestern University

Institute for Policy Research

2040 Sheridan Road

Evanston, IL 60208

and NBER

j-guryan@ @orthwestern.edu

Kyle Hyndman

Department of Economics (AE1)

Tongersestraat 53, Room A0.07

Maastricht 6211LM Netherlands

k.hyndman@maastrichtuniversity.nl
Melissa Schettini Kearney

Department of Economics

University of Maryland

3105 Tydings Hall

College Park, MD 20742

and NBER

kearney@econ.umd.edu

Erkut Y. Ozbay

Department of Economics

University of Maryland

College Park, MD 20742

erkut.ozbay@gmail.com 


\title{
Do Lottery Payments Induce Savings Behavior? Evidence from the Lab*
}

\author{
Emel Filiz-Ozbay, ${ }^{\dagger}$ Jonathan Guryan, ${ }^{\ddagger}$ Kyle Hyndman, ${ }^{\S}$ Melissa \\ Kearney and Erkut Y. Ozbay"
}

June 4, 2013

\begin{abstract}
This paper presents the results of a laboratory experiment designed to investigate whether the option of a Prize Linked Savings (PLS) product alters the likelihood that subjects choose to delay payment. By comparing PLS and standard savings products in a controlled way, we find strong evidence that a PLS payment option leads to greater rates of payment deferral than does a straightforward interest payment option of the same expected value. The appeal of the PLS option is strongest among men, self-reported lottery players, and subjects with low bank account balances. We use the results of our experiment to structurally estimate the parameters of the decision problem governing time preference, risk aversion, and probability weighting. We employ the parameter estimates in a series of policy simulations that compare the relative effectiveness of PLS products as compared to standard savings products.
\end{abstract}

JEL Codes: C91, D12, D14, D81

Keywords: prize linked savings, lotteries, risk preferences, Prelec weighting

\section{Introduction}

There is now widespread recognition that individual decision-making with regard to savings behavior often deviates from the standard neoclassical model of a risk-averse consumer

${ }^{*}$ We thank the University of Maryland, Department of Economics for its generous financial support for this research. We thank seminar participants at Penn State University (Smeal College of Business) and University College London, conference participants at the 2013 RAND Behavioral Finance Forum and the Decision Theory Conference at ITAM, as well as Matthew Embrey, Philippe Jehiel, Anthony Kwasnica and Antoine Terracol for helpful discussions. Kristian López-Vargas programmed the experiment in z-Tree and also provided excellent assistance during the experimental sessions.

${ }^{\dagger}$ Department of Economics, University of Maryland

${ }^{\ddagger}$ Institute for Policy Research, Northwestern University and NBER

${ }^{\S}$ Department of Economics (AE1), Maastricht University

IDepartment of Economics, University of Maryland and NBER

"Department of Economics, University of Maryland 
making decisions according to the tenets of expected utility theory. ${ }^{1}$ In recent years, many policies have been suggested or implemented that make use of observed deviations from the standard neoclassical model to "nudge" consumers toward increased savings. ${ }^{2}$ Notable examples include changes in default 401(k) settings such that employees are automatically enrolled in savings plans (cf, Madrian and Shea (2001)) and the "Save More Tomorrow" (SMarT) plan that has workers pre-commit to setting aside future wage increases in a savings account (Thaler and Benartzi, 2004). Chetty, Friedman, Leth-Petersen, Nielsen, and Olsen (2012) present evidence that the impact of a targeted savings policy on wealth accumulation is much larger if it affects passive choice (e.g., automatic employer contributions) versus affecting active choice (e.g., subsidies to savings).

Prize Linked Savings (PLS) accounts constitute an alternative policy innovation in the domain of savings behavior. The concept of a Prize Linked Savings account is to add a stochastic element to an otherwise standard account, such that depositors periodically receive a chance to win a specified (and potentially large) prize that is a function of deposit amounts. The idea behind PLS products is to leverage the appeal of gambling to entice people to invest in savings products that offer a positive expected return. ${ }^{3}$ The stochastic return could be in addition to some guaranteed interest payment or it could constitute the entire return. A PLS product is unlike a traditional lottery ticket in that the principal is returned to the investor. The random component of the return on savings can take the form of in-kind prizes - as is commonly offered by commercial banks in Latin America - or as a cash prize awarded to account holders as a part of a semi-regular drawing - as is the case with Britain's Premium Bonds. PLS products are new to the United States, but have existed in some form around the world for hundreds of years. Prize Linked Savings accounts are presumed to appeal to individuals' appetite for lottery-like products, either because of risk-loving preferences or probability weighting in the decision function that leads individuals to overweight the likelihood of a gain. ${ }^{4}$

\footnotetext{
${ }^{1}$ The descriptive validity of expected utility theory has been challenged by a large body of experimental literature (e.g. Starmer (2000) for a review).

${ }^{2}$ The use of this term in this context is due to Thaler and Sunstein (2008).

${ }^{3}$ Kearney, Tufano, Guryan, and Hurst (2010) provide an overview of prize-linked savings (PLS) products, including discussions of the history of such products, potential legal barriers, and descriptive evidence from some recent product roll outs in the United States.

${ }^{4}$ Nonlinear probability weighting has been put forth as an explanation for several behavioral phenomena. For example, Barberis and Huang (2008) show that such biased decision makers have a preference for skewness of returns in stocks. Sydnor (2010) argues that the over-weighting of small probabilities explains the fact that decision makers over-insure their homes against modest-scale risks. Similarly, Barseghyan, Molinari, O'Donoghue, and Teitelbaum (Forthcoming) argue that probability distortions (i.e., overweighting of claim probabilities) play a key role in determining households' deductible choices. Finally, Hu and Scott (2007) argue that longevity annuities may be more attractive to consumers than immediate annuities because they over-weight the small probability of living long enough to receive a large payment.
} 
In this paper we describe the results of a laboratory experiment designed to investigate whether the option of a PLS-type product alters the likelihood that subjects choose to save (i.e., delay payment). We also use the observed choice behavior to jointly estimate risk, discount, and probability weighting parameters under certain modeling assumptions. The popularity of PLS products in the settings in which they have been offered is often cited by policy advocates as evidence that they would be effective at encouraging savings. By comparing PLS and standard savings products in a controlled way, we are able to test whether the offer of PLS generates more savings behavior than otherwise equivalent non-PLS savings products. ${ }^{5}$

The first main contribution of this paper is to determine whether the offer of a PLS type product increases the rate at which subjects choose to defer payment (which we take as indicative of savings behavior) as compared to the the offer of a guaranteed interest payment. We establish this in a laboratory experiment run on 96 students in the University of Maryland Experimental Economics Laboratory during March 2012. We followed the wellestablished practice of using binary choices to elicit preferences paired with probabilistically determined payments. We find strong evidence that a lottery-like payout leads to greater rates of payment deferral as compared to a straightforward interest payment of the same expected value. In other words, subjects make choices such that they appear to be more patient when the option paid later is a risky gamble than when it is a sure thing. The appeal of the PLS product appears to be greatest among men, self-reported lottery players, and those who report relatively low amounts in their existing bank accounts.

The second main contribution of this paper is to use the observations from our experiment to jointly estimate decision-problem parameters under well-specified modeling assumptions. Specifically, assume decision makers have a CRRA utility function and weight probabilities according to a Prelec (1998) probability weighting function. ${ }^{6}$ As first pointed out by Yaari (1987), in models with probability weighting, one's risk attitude cannot be solely described by the curvature of the utility function, but rather, the shape of the utility function together

\footnotetext{
${ }^{5}$ Providing lottery rewards has been shown in other contexts to have a positive effect. Volpp, John, Troxel, Norton, Fassbender, and Loewenstein (2008a) ran an experiment in which lotteries were provided as a reward for taking one's required medication daily. They find that participants were significantly more likely to follow the prescribed dosage during the intervention period, but that behavior falls back to pre-intervention levels after the experiment. In a related paper, Volpp, John, Troxel, Norton, Fassbender, and Loewenstein (2008b) run a randomized experiment to study the effectiveness of lottery incentives in weight-loss programs. They find that participants subject to lottery incentive treatments weighed significantly less after 16 weeks and, despite subsequent weight gains, continued to weigh significantly less after 7 months.

${ }^{6}$ Lichtenstein, Slovic, Fischhoff, Layman, and Combs (1978) were the first to show that subjects tend to over-estimate rare events. Following the cumulative prospect theory of Tversky and Kahneman (1992), many studies, including Gonzalez and Wu (1999), Abdellaoui (2000) and Bruhin, Fehr-Duda, and Epper (2010) have found strong experimental support for an inverse $S$-shaped probability weighting function.
} 
with probability weighting jointly determine the risk attitude of a decision maker. In addition, Andersen, Harrison, Lau, and Rutström (2008) have demonstrated the importance of joint elicitation of risk and time preferences. Building on these insights, we designed our experiment to facilitate the joint elicitation and estimation of the various decision problem parameters. We adopt the theoretical framework and structural maximum likelihood methods of Andersen et al. (2008) to estimate jointly the consumer's discount factor, risk parameter of a CRRA utility function, and Prelec's probability weighting function. ${ }^{7}$ Under the assumption of linear probability weighting, our structural estimation finds that subjects are both patient and modestly risk averse with results qualitatively similar to Andreoni and Sprenger (2012). However, our results also show that a model that allows for non-linear probability weighting fits the data substantially better.

The third main contribution of this paper is to use our structural estimates in policy simulations. We consider the relative effectiveness of PLS products as compared to standard savings products. We first show theoretically that, when given a choice between an interestonly device and a PLS device with the same expected return, there is always a prize large enough (with correspondingly small probability) such that a decision maker with non-linear probability weights prefers the PLS option. We then consider a simple intertemporal choice setting in which a risk averse decision maker with non-linear probability weights chooses between present and future consumption, where future consumption can come from a combination of interest-only savings or PLS savings with the same expected return. We show that when the probability of receiving the prize is less than a threshold, the decision maker will allocate all future consumption to PLS. A corollary of these results is that the decision maker will allocate more to future consumption when PLS is available than when only interest is available. Given our structural estimation results, we find that a $0.01 \%$ probability of receiving a large prize causes subjects to increase their savings by about $4 \%$ relative to an interest only savings device with equal expected return. We show that men increase their savings more than women; those who purchase lottery tickets increase more so than those who do not; and that those with lower savings increase their savings more than those with higher savings, though the latter result is not statistically significant at conventional levels.

The paper proceeds as follows. In the next section, we provide details on our experimental design. In Section 3 we present descriptive results from our experimental data. In Section 4 we describe our structural estimation approach and results. In Section 5 we first show theoretically that non-linear probability weighting implies that PLS savings devices are preferred to interest-only devices and that they induce greater savings (for small enough

\footnotetext{
${ }^{7}$ Stott (2006) finds that among 256 models, Prelec's one-parameter weighting function is preferable to its two-parameter version and to other non-parametric models when combined with a CRRA utility function.
} 
probabilities/large enough prizes). We then conduct a number of policy experiments using our earlier parameter estimates to show the possible effects of introducing PLS savings devices. Section 6 concludes.

\section{The Experiment}

Our experiment is designed with two goals in mind. First, we are interested in observing whether savings behavior responds more to lottery, or stochastic, interest payments than to guaranteed interest payments of the same expected value. Second, we aim to estimate structural parameters of a choice problem which involves tradeoffs over time and across different degrees of risk and uncertainty. We estimate these structural parameters by jointly eliciting risk and time preferences in the manner of Andersen et al. (2008). Later, we use the estimated structural parameters to estimate the effect of the offer of PLS on savings. As a broad overview, each subject was given a set of 100 binary choices - ten decision problems, each with ten questions - which can be used to infer risk and time preferences. The decision problems were of two types: seven prize-linked savings decision problems, including a set of standard time discounting questions, and three standard Holt and Laury (2002) risk-decision problems used to isolate risk preferences. We designed this combination of questions to show whether the offer of PLS leads to more savings than the offer of a standard interest account, and to learn how behavioral responses to PLS derive from underlying preferences (e.g. whether subjects respond to PLS because they behave as if they weight probabilities linearly and have risk-seeking preferences, or engage in non-linear probability weighting with risk averse preferences). The various problems were designed to make choices that isolate parameters governing discounting, risk-preferences and probabilty weighting.

\subsection{Prize Linked Savings Decision Problems}

The innovative set of choices that constitute the main experimental contribution of this project are the seven prize-linked savings decision problems. The crucial aspect of these problems is that they presented subjects with the option of a certain payment early (Option A) versus a payment with interest later (Option B). Table 1 presents these seven sets of decision problems. The first set (a) is characterized by the choice between a certain payment early versus a certain payment later, where early and later refer to 3 and 5 weeks from the date of the experiment, respectively. All of the payments are scheduled to be in the future to abstract from issues of immediate reward. The practical reason for this design is so that our estimation procedure is not encumbered by having to estimate hyperbolic discounting 
parameters. The specific questions in decision problem set (a) involve the choice between Option A, a fixed amount of $\$ 20$ paid in 3 weeks versus Option B, which adds a guaranteed interest payment, ranging from $\$ 1$ to $\$ 10$, to be paid in 5 weeks. This set of questions constitutes standard time discounting questions, and we expect a greater interest payment to induce greater rates of savings behavior (or delayed payment).

More interestingly, decision problems (b) and (c) present the choice between a certain early payment of $\$ 20$ in 3 weeks, and a binary lottery payment in 5 weeks. Questions (1) - (10) in these two sets of problems involve expected interest payments of equal value to the corresponding question in problem set (a), but the payment is stochastic in nature. To explain the notation, take, for example, question (1) of problem set (b): the notation $[(30,20) ;(0.10,0.90)]$ represents a lottery with a $10 \%$ chance of winning $\$ 30$ and a $90 \%$ chance of winning $\$ 20$, for an expected payment of $\$ 21$.

In general, looking at decision problems (a) - (c), the $i^{\text {th }}$ question for problem (a) corresponds between a choice of $\$ 20$ in three weeks or $\$ 20+i$ in five weeks; this is precisely the expected value of Option B for the $i^{\text {th }}$ question for both decision problems (b) and (c). Therefore, if the non-linear probability weighting is ruled out, a risk neutral decision maker should have the same switching point (sp) for all three decision problems, meaning they would move from early to later payment at the same expected interest payment in all three cases. Similarly, a risk averse decision maker with linear probability weighting would require an additional payment to take the risky option, and hence would be expected to switch later in problems (b) and (c). The lottery payment offered in problem set (c) is riskier than than in (b); therefore, we would also expect a later switching point in problem (c). That is, under the assumption of a neoclassical risk averse decision maker, $s p(a) \leq s p(b) \leq s p(c)$. However, if, as many previous studies have found, subjects over-weight low probability events, then this should increase the attractiveness of Option B in the choice problems that involve a lottery payment. If the switching points (to delayed payment) are found to be earlier in sets (b) and (c), as compared to set (a), that would provide evidence suggesting that prize-linked savings products could be an effective way to entice individuals to save.

Observe in Table 1 that decision problems (d) - (f) have the same general characteristics as decision problems (a) - (c). Two alterations are that the base payment is $\$ 15$ and the payment dates are in 2 weeks for Option A and in 6 weeks for Option B. A fourth problem set $(\mathrm{g})$ is added in this series to allow us to make comparisons with higher prize and lower probability lotteries. The two riskier lotteries in this set involve a top payoff of $\$ 115$ in problem set (f) and $\$ 215$ in problem set (g). Crucially, the odds adjust accordingly, so that the expected interest payment remains constant across the $i^{\text {th }}$ question for all sets $(\mathrm{d})-(\mathrm{g})$. 
Table 1: Prize-Linked Savings Decision Problems

(a) Standard Time

\begin{tabular}{cc}
\hline $\begin{array}{c}\text { Option A } \\
(3 \text { weeks })\end{array}$ & $\begin{array}{c}\text { Option B } \\
(5 \text { weeks })\end{array}$ \\
\hline 20 & 21 \\
20 & 22 \\
20 & 23 \\
20 & 24 \\
20 & 25 \\
20 & 26 \\
20 & 27 \\
20 & 28 \\
20 & 29 \\
20 & 30 \\
\hline
\end{tabular}

(d) Standard Time (b) Certain Early vs. Later Lottery

\begin{tabular}{cc}
\hline $\begin{array}{c}\text { Option A } \\
(3 \text { weeks })\end{array}$ & $\begin{array}{c}\text { Option B } \\
(5 \text { weeks })\end{array}$ \\
\hline 20 & $(30,20) ;(0.10,0.90)$ \\
20 & $(30,20) ;(0.20,0.80)$ \\
20 & $(30,20) ;(0.30,0.70)$ \\
20 & $(30,20) ;(0.40,0.60)$ \\
20 & $(30,20) ;(0.50,0.50)$ \\
20 & $(30,20) ;(0.60,0.40)$ \\
20 & $(30,20) ;(0.70,0.30)$ \\
20 & $(30,20) ;(0.80,0.20)$ \\
20 & $(30,20) ;(0.90,0.10)$ \\
20 & $(30,20) ;(1.00,0.00)$ \\
\hline
\end{tabular}

(e) Certain Early vs. Later Lottery

Option A Option B

\begin{tabular}{cc}
$(2$ weeks $)$ & $(6$ weeks $)$ \\
\hline 15 & 16 \\
15 & 17 \\
15 & 18 \\
15 & 19 \\
15 & 20 \\
15 & 21 \\
15 & 22 \\
15 & 23 \\
15 & 24 \\
15 & 25
\end{tabular}

(c) Certain Early vs. Later Lottery

\begin{tabular}{cc}
\hline $\begin{array}{c}\text { Option A } \\
\text { (3 weeks })\end{array}$ & $\begin{array}{c}\text { Option B } \\
(5 \text { weeks })\end{array}$ \\
\hline 20 & $(120,20) ;(0.01,0.99)$ \\
20 & $(120,20) ;(0.02,0.98)$ \\
20 & $(120,20) ;(0.03,0.97)$ \\
20 & $(120,20) ;(0.04,0.96)$ \\
20 & $(120,20) ;(0.05,0.95)$ \\
20 & $(120,20) ;(0.06,0.94)$ \\
20 & $(120,20) ;(0.07,0.93)$ \\
20 & $(120,20) ;(0.08,0.92)$ \\
20 & $(120,20) ;(0.09,0.91)$ \\
20 & $(120,20) ;(0.10,0.90)$ \\
\hline
\end{tabular}

(f) Certain Early vs. Later Lottery

\begin{tabular}{cc}
\hline $\begin{array}{c}\text { Option A } \\
(2 \text { weeks })\end{array}$ & $\begin{array}{c}\text { Option B } \\
(6 \text { weeks })\end{array}$ \\
\hline 15 & $(115,15) ;(0.01,0.99)$ \\
15 & $(115,15) ;(0.02,0.98)$ \\
15 & $(115,15) ;(0.03,0.97)$ \\
15 & $(115,15) ;(0.04,0.96)$ \\
15 & $(115,15) ;(0.05,0.95)$ \\
15 & $(115,15) ;(0.06,0.94)$ \\
15 & $(115,15) ;(0.07,0.93)$ \\
15 & $(115,15) ;(0.08,0.92)$ \\
15 & $(115,15) ;(0.09,0.91)$ \\
15 & $(115,15) ;(0.10,0.90)$ \\
\hline
\end{tabular}

(g) Certain Early vs. Later Lottery

\begin{tabular}{cc}
\hline $\begin{array}{c}\text { Option A } \\
(3 \text { weeks })\end{array}$ & $\begin{array}{c}\text { Option B } \\
(5 \text { weeks })\end{array}$ \\
\hline 15 & $(215,15) ;(0.005,0.995)$ \\
15 & $(215,15) ;(0.010,0.990)$ \\
15 & $(215,15) ;(0.015,0.985)$ \\
15 & $(215,15) ;(0.020,0.980)$ \\
15 & $(215,15) ;(0.025,0.975)$ \\
15 & $(215,15) ;(0.030,0.970)$ \\
15 & $(215,15) ;(0.035,0.965)$ \\
15 & $(215,15) ;(0.040,0.960)$ \\
15 & $(215,15) ;(0.045,0.955)$ \\
15 & $(215,15) ;(0.050,0.950)$ \\
\hline
\end{tabular}




\section{$2.2 \quad$ Risk Decision Problems}

In addition to the prize linked savings problems described above, subjects were presented with three sets of risk decision problems. These are not relevant to the specific question of the appeal of prize-linked savings products, but they are necessary to elicit risk preferences separately from discount rates, which will help to identify the underlying reason for any attractiveness of PLS that we find.

Table 2: Risk Decision Problems

(h) Standard Holt-Laury

\begin{tabular}{cc}
\hline $\begin{array}{c}\text { Option A } \\
(2 \text { weeks })\end{array}$ & $\begin{array}{l}\text { Option B } \\
(2 \text { weeks })\end{array}$ \\
\hline$(25,21) ;(0.10,0.90)$ & $(43,7) ;(0.10,0.90)$ \\
$(25,21) ;(0.20,0.80)$ & $(43,7) ;(0.20,0.80)$ \\
$(25,21) ;(0.30,0.70)$ & $(43,7) ;(0.30,0.70)$ \\
$(25,21) ;(0.40,0.60)$ & $(43,7) ;(0.40,0.60)$ \\
$(25,21) ;(0.50,0.50)$ & $(43,7) ;(0.50,0.50)$ \\
$(25,21) ;(0.60,0.40)$ & $(43,7) ;(0.60,0.40)$ \\
$(25,21) ;(0.70,0.30)$ & $(43,7) ;(0.70,0.30)$ \\
$(25,21) ;(0.80,0.20)$ & $(43,7) ;(0.80,0.20)$ \\
$(25,21) ;(0.90,0.10)$ & $(43,7) ;(0.90,0.10)$ \\
$(25,21) ;(1.00,0.00)$ & $(43,7) ;(1.00,0.00)$ \\
\hline
\end{tabular}

(i) Standard Holt-Laury

\begin{tabular}{cc}
\hline $\begin{array}{c}\text { Option A } \\
(6 \text { weeks })\end{array}$ & $\begin{array}{c}\text { Option B } \\
(6 \text { weeks })\end{array}$ \\
\hline$(20,15) ;(0.005,0.995)$ & $(400,7) ;(0.005,0.995)$ \\
$(20,15) ;(0.010,0.990)$ & $(400,7) ;(0.010,0.990)$ \\
$(20,15) ;(0.015,0.985)$ & $(400,7) ;(0.015,0.985)$ \\
$(20,15) ;(0.020,0.980)$ & $(400,7) ;(0.020,0.980)$ \\
$(20,15) ;(0.025,0.975)$ & $(400,7) ;(0.025,0.975)$ \\
$(20,15) ;(0.030,0.970)$ & $(400,7) ;(0.030,0.970)$ \\
$(20,15) ;(0.035,0.965)$ & $(400,7) ;(0.035,0.965)$ \\
$(20,15) ;(0.040,0.960)$ & $(400,7) ;(0.040,0.960)$ \\
$(20,15) ;(0.045,0.955)$ & $(400,7) ;(0.045,0.955)$ \\
$(20,15) ;(0.050,0.950)$ & $(400,7) ;(0.050,0.950)$ \\
\hline
\end{tabular}

(j) Standard Holt-Laury

\begin{tabular}{cc}
\hline $\begin{array}{c}\text { Option A } \\
(6 \text { weeks })\end{array}$ & $\begin{array}{c}\text { Option B } \\
(6 \text { weeks })\end{array}$ \\
\hline$(22,14) ;(0.01,0.99)$ & $(150,8) ;(0.01,0.99)$ \\
$(22,14) ;(0.02,0.98)$ & $(150,8) ;(0.02,0.98)$ \\
$(22,14) ;(0.03,0.97)$ & $(150,8) ;(0.03,0.97)$ \\
$(22,14) ;(0.04,0.96)$ & $(150,8) ;(0.04,0.96)$ \\
$(22,14) ;(0.05,0.95)$ & $(150,8) ;(0.05,0.95)$ \\
$(22,14) ;(0.06,0.94)$ & $(150,8) ;(0.06,0.94)$ \\
$(22,14) ;(0.07,0.93)$ & $(150,8) ;(0.07,0.93)$ \\
$(22,14) ;(0.08,0.92)$ & $(150,8) ;(0.08,0.92)$ \\
$(22,14) ;(0.09,0.91)$ & $(150,8) ;(0.09,0.91)$ \\
$(22,14) ;(0.10,0.90)$ & $(150,8) ;(0.10,0.90)$ \\
\hline
\end{tabular}

Table 2 presents these choice sets, labeled as problem sets (h), (i), and (j). Problem set (h) presents two lottery options, both paying out in two weeks. Problem sets (i) and (j) present two lotteries, both which pay out in six weeks. These are designed as standard risk elicitation problems, as introduced by Holt and Laury (2002) and have been used by many subsequent researchers, including Andersen et al. (2008). In these problems, the expected value of Option $\mathrm{A}$ is higher than the expected value of Option B in initial questions, before switching in later questions to favor Option B. For example, in problem set $(\mathrm{h})$, in the first question, Option A has an expected value of 21.4 and Option B has an expected value of 10.6. 
But Option B offers a top payoff of 43, as compared to a top prize of 25 in Option A. Only a sufficiently risk-loving consumer or someone with an extreme form of non-linear probability weighting would choose Option B in this question. A risk-neutral consumer should switch from choosing A to B when the expected value of Option B becomes greater, which occurs between questions 4 and 5 for all three problems, while a risk averse decision maker would switch later. In question 10 of set (h), Option A has an expected value of 25 and Option B has an expected value of 43. No rational subject who understands the instructions and is playing for real would choose Option A in this question.

One innovation of our experimental design as compared to previous experiments eliciting risk parameters is to include a wider range of probability values and prize values. The experimental literature that estimates the probability weighting in rank-dependent models often uses probabilities between 0.1 and 0.9 for the uncertain outcomes (Andersen et al. (2008), Harrison and Rutström (2008) when they analyzed Holt and Laury (2002)). In the questions included in our experiment, we extended the range of probabilities to include 0.005 and 0.995 . The outcomes varied in a range that contains both low and high stakes for undergraduate subjects, namely between $\$ 7$ and $\$ 400$. As such, we cover a reasonably wide range of probabilities and outcomes for our subject pool.

\subsection{Experimental Procedures}

University of Maryland (UMD) undergraduate students were recruited to participate in this experiment in the UMD Department of Economics Experimental Laboratory. A total of 96 students participated in one of six sessions held on 3/28/2012 and 3/29/2012. ${ }^{8}$ Subjects were presented with the experimental problems using individual, confidential computer kiosks. The experiment was programmed in z-Tree (Fischbacher, 2007). A pen and paper survey was administered at the end of the session. Appendix A includes the experiment instructions, while Appendix B contains the survey. In addition to a $\$ 7$ participation fee and $\$ 3$ for completing the post-experiment survey, subjects were paid for one random decision. ${ }^{9}$

To determine which of the 100 decisions would be used to determine an individual student's additional payment, each subject rolled a 10-sided die twice, first to determine the decision problem and then to determine the question. After the specific question was determined, depending on the option chosen, subjects rolled the same die (up to three additional times) to determine their payment. On average, based on their decisions in the experiment,

\footnotetext{
${ }^{8}$ We selected these dates so that the payment dates did not correspond to final exams week or a holiday.

${ }^{9}$ Under a monotonicity assumption, Azriele, Chambers, and Healy (2012) show that this is (essentially) the only incentive compatible mechanism to pay subjects. Cubitt, Starmer, and Sugden (1998) show that this incentive scheme generates reliable experimental data (see also Azriele et al. (2012) for further discussion and references).
} 
subjects received $\$ 18.91$ ( $\min \$ 7$; $\max \$ 120)$, with payments occurring $2,3,5$ or 6 weeks after the experiment. After the payment amount and date were determined, the subject wrote their name on the outside of an envelope and the payment amount and date on the inside of the envelope. The envelope was then returned to the experimenter, filled with the appropriate amount of money and locked in a secure location. The day before the payment date, subjects were sent an email reminding them that they could pick up their envelope the next day between 9:00am and 5:00pm. Note that regardless of the payment date, subjects would have to return to the experimental lab to receive their payment. Therefore, although the experiment imposed an additional cost on subjects, the cost was the same regardless of the payment date. All subjects came to receive their payments on their appointed day.

\section{Basic Results}

We begin our empirical analysis by presenting basic statistics on subject choices in the experiment. These results show how basic patterns in behavior varied across the different problems. Subjects' behavioral choices are captured succinctly by two measures: the fraction of subjects who chose to delay payment (i.e., chose option B) in each problem, and the average switch point for each problem. We define the switch point to be the first question at which the subject chose option B. Recall that there are 10 questions, and that they are ordered so that once a subject chooses option $\mathrm{B}$ it is not rational to choose option A later. ${ }^{10}$

\subsection{PLS and the Decision to Save}

Table 3 presents the results of the decision problems featuring PLS and standard interest options. The top panel of the table shows results for problems (a) - (c) and the bottom panel shows results for problems (d) - (g). A large fraction of subjects chose to delay payment, or to save. In particular, in problem (a) almost half of the subjects (47 percent) were willing to wait an extra two weeks for just one additional guaranteed dollar, and in problem (d) 38 percent of the subjects were willing to wait an extra 4 weeks for one guaranteed additional dollar. $^{11}$

The problems are designed so that it is natural to compare the PLS problems (b) and (c) to the standard interest problem (a), and to compare PLS problems (e), (f) and (g) to

\footnotetext{
${ }^{10}$ Only four subjects chose option A after previously choosing option B on any problem. Since the switch point is not clearly defined for these subjects, we excluded them from the switch point regressions.

${ }^{11}$ Perhaps this revealed patience reflects, in part, our experiment's focus on future payment times exclusively. No question offered the option of immediate payment, so the design of the experiment explicitly avoided a role for present-biased preferences.
} 
Table 3: Savings rate and switch point responses to PLS v. standard interest questions

(i) Problems (a) - (c)

\begin{tabular}{lccc}
\hline & Std. Int. & PLS & PLS \\
\hline Problem & $(\mathrm{a})$ & $(\mathrm{b})$ & $(\mathrm{c})$ \\
Fraction delay payment: Question 1 & 0.47 & $0.63^{* * *}$ & $0.69^{* * *}$ \\
Fraction delay payment: All questions & 0.76 & $0.82^{* * *}$ & $0.81^{*}$ \\
& 3.4 & $2.7^{* * *}$ & 2.9 \\
Average switch point (s.d.) & $(2.9)$ & $(2.7)$ & $(3.3)$ \\
& 2 & 1 & 1 \\
\hline Median switch point & & & \\
\hline
\end{tabular}

(ii) Problems (d) - (g)

\begin{tabular}{lclll}
\hline & Std. Int. & PLS & PLS & PLS \\
\hline Problem & $(\mathrm{d})$ & $(\mathrm{e})$ & $(\mathrm{f})$ & $(\mathrm{g})$ \\
Fraction delay payment: Question 1 & 0.38 & $0.54^{* * *}$ & $0.66^{* * *}$ & $0.71^{* * *}$ \\
Fraction delay payment: All questions & 0.68 & $0.77^{* * *}$ & $0.81^{* * *}$ & $0.81^{* * *}$ \\
& 4.1 & $3.3^{* * *}$ & $2.8^{* * *}$ & $3.0^{* * *}$ \\
Average switch point (s.d.) & $(3.4)$ & $(3.1)$ & $(3.2)$ & $(3.5)$ \\
\hline Median switch point & 3 & 1 & 1 & 1 \\
\hline
\end{tabular}

Notes: Asterisks indicate level of significance for $t$-test of equality relative to the corresponding standard interest problem (a v. b, c; d v. e, f, g). ${ }^{* * *}: p<0.01,{ }^{* *}: p<0.05,{ }^{*}: p<0.10$.

the standard interest problem (d). Considering the delayed payment option in each case, problem (c) is a mean-preserving spread of problem (b), which is a mean preserving spread of problem (a). Similarly, problem (f) is a mean-preserving spread of (e), which is a meanpreserving spread of (d). ${ }^{12}$ Thus, standard expected utility theory predicts that a risk-averse decision maker without non-linear probability weighting should prefer option B in a given question of problem (a) over the option B of the same question in problems (b) and (c). The similar comparison holds for problem (d) and problems (e) and (f). Our empirical findings are in direct contrast to this prediction. These results reject the standard model in which a risk averse agent maximizes expected utility (i.e. linear probability weighting).

Comparing the PLS problems to their corresponding standard certain interest problems, we find that subjects were more likely to save when presented with PLS opportunities. Whereas 47 percent of subjects chose to delay payment at question 1 of problem (a), 63 and 69 percent of subjects chose to delay payment at question 1 of the PLS problems (b) and

\footnotetext{
${ }^{12}$ Problems (f) and (g) vary on two dimensions - variance and the delay of the payment - making the comparison less simple. This variation helps to identify the parameters of the utility function in the structural estimation.
} 
(c), respectively. These PLS savings rates were significantly greater than the savings rate for problem (a) $(p<0.001)$. We find a similar pattern when we compare initial savings rates for problems (e) and (f), which presented savings choices with payments that were delayed longer relative to problem (d). Whereas 38 percent of subjects chose to delay payment at question 1 of problem (d), 54 and 66 percent of subjects chose to delay payment at question 1 of the PLS problems (e) and (f), respectively. It is more difficult to compare the results from problem (g) to any one standard saving problem because the stakes are similar to problem (d) and the time horizon is similar to problem (a). However, the pattern of behavior matches what we see for the other PLS problems. 71 percent of subjects chose to delay payment at the first question of problem $(\mathrm{g})$.

We observed a similar pattern when we considered the responses to all ten questions. Whereas 76 percent of choices were for option B, the delayed payment, for the standard interest problem (a), 82 and 81 percent of choices were for option B in the corresponding PLS problems, (b) and (c) respectively. The former is statistically different from the rate for problem (a) at the 1-percent level; the latter at the 10-percent level. Similarly, whereas 68 percent of choices were for delayed payment for the standard interest problem (d), 77, 81 and 81 percent of choices were to delay payment in the corresponding PLS problems, (e), (f) and (g) respectively. All three of these rates are significantly distinct from the rate for option (d) at the 1-percent level.

The design of the experiment allows us to measure another dimension along which savings responses to PLS and standard interest offerings were different. The incremental variation in the questions allows us to measure the minimum expected return necessary to induce initial non-savers to choose to save. In each problem, subsequent questions offered higher expected returns to the saving option, in the form of a higher certain payment in problems (a) and (d), and in the form of an increased probability of a high payment in the PLS problems. The expected return to choosing option B increased from question 1-10 in the same way for problems $(\mathrm{a})-(\mathrm{c})$, and for problems $(\mathrm{d})-(\mathrm{g})$.

For each problem, by the time subjects reached question 10, which offered the highest expected returns for option $B$, the vast majority chose to save. There was significant variation, however, in how high an expected return was necessary to induce subjects to save. To document this variation, we present the average (and standard deviation) of the switch point for each problem. The switch points for problems (a) - (c) are shown in the third row of Table 3. On average when presented with problem (a), subjects switched to option B after 3.4 questions. There was also a good deal of variation in switch points. The standard deviation in switch points for problem (a), for example, was 2.9, suggesting that there was a significant amount of heterogeneity in saving preferences. 
In comparison, the switch points for the PLS problems (b) and (c) (2.7 and 2.9, respectively) were earlier on average than for the standard interest problem (a). In other words, PLS required lower expected returns to induce subjects to save. The $p$-values of the differences in switch points relative to problem (a) were less than 0.001 and 0.111 , respectively.

We observe similar patterns in the switch points for problems $(d)-(g)$. The average switch point for the standard interest problem (d) was 4.1. The average switch points for the three PLS problems with corresponding expected returns were significantly earlier. The average switch points for problems (e) - (g) were 3.3, 2.8 and 3.0, respectively. Each was statistically significantly different from problem (d)'s switch point ( $p<0.001$ in each case).

Taken together, these results demonstrate that PLS induced more saving behavior than standard interest. Subjects were more likely to save when presented with the initial PLS choice than when presented with the initial standard interest choice. Furthermore, lower expected returns were required to induce subjects to save when the returns were presented as PLS than when they were presented as standard certain interest.

\subsection{Risk Elicitation Problems}

The above results show that PLS is an attractive option at increasing savings; however, they do not allow us to distinguish between which of two underlying causes lead to the result: convex utility or non-linear probability weighting. To resolve this issue, we now turn to the results of the decision problems for the risk elicitation problems. In all three of our risk problems, a risk-neutral decision maker with linear probability weights would switch between the fourth and fifth question. Both convex utility and non-linear probability weighting would lead to earlier switch points, while concave utility would lead to later switch points. ${ }^{13}$ Table 4 provides the summary results. The main finding is that for all three problems, the switch point occurs significantly later than the fifth question according to a Wilcoxon signed-rank test $(p<0.01$ in all cases). Thus, it must be that subjects utility is concave in money. Assuming that subjects have stable preferences across different decision problems, this allows us to conclude that non-linear probability weighting is the main driver for the attractiveness of PLS rather than convex utilities.

\subsection{Heterogeneity in responses to PLS}

The results in Table 3 also suggest significant heterogeneity across subjects in savings preferences. We next examine how savings choices and preferences towards PLS varied across

\footnotetext{
${ }^{13}$ Concave utility and non-linear probability weighting push the switching point in opposite directions with respect to the switch point of a decision maker with risk neutral and linear probability weighting.
} 
Table 4: Summary Statistics: Risk Elicitation Problems

\begin{tabular}{lccc}
\hline Problem & $(\mathrm{h})$ & $(\mathrm{i})$ & $(\mathrm{j})$ \\
Fraction risky gamble: Question 1 & 0.00 & 0.30 & 0.26 \\
Fraction risky gamble: All questions & 0.41 & 0.48 & 0.49 \\
\multirow{2}{*}{ Average switch point (s.d.) } & 6.9 & 6.3 & 6.2 \\
& $(1.4)$ & $(4.0)$ & $(3.7)$ \\
\hline Median switch point & 7 & 7.5 & 6 \\
\hline
\end{tabular}

subjects. In particular, we explore heterogeneity across three dimensions: (a) self-reported lottery players versus self-reported lottery abstainers; (b) male versus female; and (c) those with a combined balance in their savings and checking accounts of more or less than $\$ 1000$. In our study sample, gender and lottery status were correlated, but neither was strongly correlated with having a high account balance. Female subjects were less likely than male subjects to be lottery players (21 versus 50 percent). About half of lottery abstainers were female, whereas 82 percent of lottery players were male.

Table 5 presents estimated effects of PLS on the two outcomes - savings rates and switch points - separately by status for each of these three comparison sets. Panel (i) reports effects and differences by lottery status; panel (ii) reports effects and differences by gender; and panel (iii) reports effects and differences by savings status (high/low). The first column reports the share of the sample defined by the particular characteristic. The second column reports the difference in the fraction of the respective group who chose option B in the PLS problems relative to the same fraction for the standard interest problems, as estimated by a regression that pools responses from questions (a) - (g). The third column reports the PLSstandard interest difference in average switch points. Rows 1-2, 4-5 and 7-8 report simple PLS-standard interest differences in the relevant outcome. Row 3 reports the difference-indifferences, defined to be the lottery PLS-standard interest difference minus the non-lottery PLS-standard interest difference, and similarly for rows 6 and $9 .{ }^{14}$

Lottery players were 16.3 percent more likely to save when presented with a PLS option than when presented with a standard interest savings option. Lottery players who did not

\footnotetext{
${ }^{14}$ All reported coefficients are estimated from regressions of an indicator for choosing option B ("Delay payment") or the switch point on an indicator for the PLS questions interacted with indicators for both mutually exclusive groups (e.g. males and females) and an indicator for one of the groups (i.e. lottery player, female, high savings). The estimates shown in rows 1-2, 4-5 and 7-8 report the coefficient on the interactions of the PLS indicator and the group indicators. The estimates shown in rows 3,6 and 9 show the estimated difference in the estimated PLS effect between the two groups (e.g. male and female). All regressions reported in the table also allow a different intercept for problems (a) - (c) versus problems (d) (g), and only include responses to problems (a) - (g). In the "Delayed payment" regressions, an observation is a question answered by a subject in a problem. In the "switch point" regressions, observations are at the problem by subject level.
} 
Table 5: Heterogeneous responses to PLS v. standard interest

\begin{tabular}{|c|c|c|c|c|}
\hline & & & \multicolumn{2}{|c|}{ PLS v. Standard interest } \\
\hline & Subgroup: & Share of sample & $\Delta$ Delay payment & $\Delta$ Switch point \\
\hline & Lottery player & 0.396 & $\begin{array}{c}0.163^{* * *} \\
(0.037)\end{array}$ & $\begin{array}{c}-1.621^{* * *} \\
(0.395)\end{array}$ \\
\hline \multirow[t]{3}{*}{ (i) } & Not lottery player & 0.604 & $\begin{array}{l}0.040^{* *} \\
(0.018)\end{array}$ & $\begin{array}{r}-0.347^{*} \\
(0.181)\end{array}$ \\
\hline & $\begin{array}{l}\text { Lottery }- \text { Not } \\
(\Delta-\text { in }-\Delta)\end{array}$ & & $\begin{array}{l}0.122^{* * *} \\
(0.042)\end{array}$ & $\begin{array}{l}-1.274^{* * *} \\
(0.436)\end{array}$ \\
\hline & Female & 0.354 & $\begin{array}{c}0.024 \\
(0.030)\end{array}$ & $\begin{array}{r}-0.138 \\
(0.303)\end{array}$ \\
\hline \multirow[t]{3}{*}{ (ii) } & Male & 0.646 & $\begin{array}{l}0.124^{* * *} \\
(0.024)\end{array}$ & $\begin{array}{l}-1.223^{* * *} \\
(0.248)\end{array}$ \\
\hline & $\begin{array}{l}\text { Female }- \text { male } \\
(\Delta-\text { in }-\Delta)\end{array}$ & & $\begin{array}{c}-0.110^{* *} \\
(0.038)\end{array}$ & $\begin{array}{l}1.085^{* * *} \\
(0.393) \\
\end{array}$ \\
\hline & Savings $>\$ 1000$ & 0.490 & $\begin{array}{c}0.058^{* *} \\
(0.028)\end{array}$ & $\begin{array}{r}-0.544^{*} \\
(0.282)\end{array}$ \\
\hline \multirow[t]{3}{*}{ (iii) } & Savings $\leq \$ 1000$ & 0.510 & $\begin{array}{l}0.118^{* * *} \\
(0.026)\end{array}$ & $\begin{array}{l}-1.146^{* * *} \\
(0.279)\end{array}$ \\
\hline & $\begin{array}{l}\text { High/low savings } \\
(\Delta-\text { in }-\Delta)\end{array}$ & & $\begin{array}{r}-0.060 \\
(0.038)\end{array}$ & $\begin{array}{r}-0.602 \\
(0.397)\end{array}$ \\
\hline & $\mathrm{N}$ & & 6720 & 644 \\
\hline
\end{tabular}

Note: Each entry in rows 1, 2, 4, 5, 7 and 8 is the difference in the fraction of subjects choosing option B (column 1) or the difference in average switch point (column 2) in PLS versus standard interest questions. PLS questions b and $\mathrm{c}$ are compared with standard interest question a; PLS questions $\mathrm{e}, \mathrm{f}$ and $\mathrm{g}$ are compared with standard interest question d. The differences are estimated in an OLS regression that pools responses from questions a-g. The entries in rows 3, 6 and 9 show the difference in PLS-standard interest differences between lottery and non-lottery players (row 3), female and male subjects (row 6), and between subjects with more and less than $\$ 1000$ in their checking and savings accounts (row 9). "Savings $>\$ 1000$ " is an indicator for subjects whose combined reported savings plus checking account balance is greater than $\$ 1000$. Standard errors reported in parentheses are robust to heteroskedasticity and account for subject-level correlation in random errors. Asterisks indicate standard levels of statistical significance. ${ }^{* * *}: p<0.01,{ }^{* *}: p<0.05,{ }^{*}: p<0.10$.

initially choose to save in question 1 also required a lower expected return to be induced to save when it came in the form of PLS as compared with standard interest. On average, lottery players switched from option A to option B 1.6 questions earlier when presented with a PLS option than when presented with a standard interest option. Both of these PLS-standard interest differences were statistically significant at the 1-percent level. Subjects who did not report being regular lottery players exhibited similar patterns, though the magnitudes of the differences were significantly less pronounced. Lottery non-players were 4.0 percent more likely to save when presented with PLS as compared with standard interest options; they switched from non-saving to saving on average 0.3 questions earlier when faced with 
PLS as compared with standard interest options. The third row shows the difference in these differences between lottery players and non-players. Both differences are significantly different: Lottery players were induced to save more by PLS, and required lower expected returns to be induced to save by PLS. ${ }^{15}$

The next panel of the table shows results broken out by gender. Females showed no differential savings response to PLS versus standard interest. Similarly, switch points among female subjects were not significantly different for PLS and standard interest problems. In contrast, male subjects were more likely to save when presented with PLS savings options (12.4 percent higher savings rates, $p<0.01$ ) and among male subjects significantly lower expected returns were necessary to induce a switch from not saving to saving when the returns were in the form of PLS than when they were presented as standard interest (average switch point 1.2 questions earlier, $p<0.01$ ). The difference in differences (PLS v. standard interest, female v. male) for the fraction choosing to save and the switch point were significant at the 5 percent and 1 percent levels, respectively. ${ }^{16}$

One motivation for PLS is that it might induce saving among individuals who do not currently save much. Support for this hypothesis comes from two facts: low-income individuals have very low savings rates, but devote a disproportionate amount of their expenditures to lottery tickets (Kearney (2005)). Because the experimental sample was drawn from undergraduates, we are not able to meaningfully compare subjects based on current or permanent income. Instead, to address this question, we compare subjects based on their reported savings. The bottom panel of the table shows results broken out between subjects who reported a combined checking and savings account balance of greater than $\$ 1000$ versus those who reported a balance less than or equal to $\$ 1000 .{ }^{17}$ This split divides the sample essentially in half. Among each group, we observed stronger savings responses to PLS than to standard interest. Subjects with more than $\$ 1000$ in combined balances saved 5.8 percent more often when presented with PLS than when presented with standard interest options. The corresponding difference was 11.8 percent among subjects with combined balances less than $\$ 1000$. The difference in these relative responses to PLS is not significant at conventional levels, but the p-value of the difference is 0.12 . We saw a similar pattern for switch points.

\footnotetext{
${ }^{15}$ Guryan and Kearney (2008) provide evidence of misperceptions of probabilities among lottery players, though that work documents an apparent belief in winning "streaks" or more specifically "lucky stores" and does not examine overweighting in particular.

${ }^{16}$ Previous studies have found that women tend to avoid risky options more than men (e.g. Croson and Gneezy (2009)). Fehr-Duda, de Gennaro, and Schubert (2006) and Booij, van Praag, and van de Kuilen (2010) find that differences in probability weighting rather than risk parameters account for more risk averse behavior observed in women.

${ }^{17}$ Admittedly, this is an arbitrary distinction, but given our subject pool consists entirely of undergraduate students, we presume that few are accumulating assets in the form of real estate or stocks and that most are saving for short-term goals. Having $\$ 1,000$ in savings thus seemed like a potentially relevant measure.
} 
Among subjects with more than $\$ 1000$ in combined savings, switch points were 0.5 questions earlier for PLS than standard interest problems. Among those with less than $\$ 1000$, switch points were 1.1 questions earlier. The double difference in switch points was not statistically significant at conventional levels, but the p-value of the difference was 0.13 . The results presented in Table 5 demonstrate that responses to PLS were stronger among lottery players than among lottery abstainers, among males than among females, and among those with low savings/checking account balances than among those with high account balances. The correlation in these characteristics - particularly the relationship between gender and lottery play - raises the possibility that a pair-wise comparison picks up the heterogeneity in responses to PLS associated with a correlated characteristic (e.g. that the male-female difference in response is driven by the male-female difference in lottery play). We explored this question by estimating a regression model that allowed responses to PLS to vary by gender, lottery status and savings/checking account status simultaneously. Specifically, we

estimated regressions in which the dependent variable was either an indicator for choosing option B or the switch point and the regressors were an indicator for PLS, indicators for female, lottery player, and $>\$ 1000$ in combined savings, and interactions between the PLS indicator and each of the three heterogeneity indicators. The results from those two regressions are presented in Table C.1 and are qualitatively the same as the results presented in Table 5. Holding constant gender and savings account status, lottery players were relatively more responsive to PLS than non-lottery players. Holding constant lottery status and savings account status, female subjects were relatively less responsive to PLS than males. Holding constant gender and lottery status, subjects with less than $\$ 1000$ in combined savings and checking accounts were relatively more responsive to PLS than those with less than $\$ 1000$.

\section{Structural Estimation of Choice Parameters}

The results presented so far indicate that subjects, on average, chose to save more, and were induced to save with lower interest rates, by PLS than by standard savings accounts. We have also documented significant heterogeneity in relative preferences for PLS versus standard interest savings accounts. This heterogeneity points to variation in preferences for risk, discounting and incorporation of probabilities. The design of the experiment presents an opportunity to jointly measure these important underlying parameters. The experiment presented subjects with choices that varied in the delay until payment, the amount of risk, and the reliance on small probabilities. In this section, we take this opportunity to estimate a structural model that jointly estimates discounting, risk-preference and probability weighting parameters. We follow the important work of Andersen et al. (2008), who demonstrate the 
necessity of estimating discounting and risk preferences jointly. In the next section, we present the framework used to estimate the parameters for the full sample. Subsequently, we show how the estimated parameters vary along the dimensions shown in the heterogeneity analysis from the previous section.

\subsection{The Consumer Choice Problem}

We seek to estimate the underlying parameters of a stochastic cumulative prospect theory model with risk parameters and time discounting. Particularly, we extend the structural model of Andersen et al. (2008) by allowing probability weighting. The basic elements are as follows: (i) we assume that subjects have a Bernoulli utility function of the form $u(x)=\frac{x^{1-\rho}-1}{1-\rho}$, where $\rho$ is the risk parameter of the subject; ${ }^{18}$ (ii) we assume that subjects use a probability weighting function, and adopt the one-parameter form, $w(p)=e^{-(-\ln p)^{\alpha}}$ from Prelec (1998); ${ }^{19}$ and (iii) we let $r \geq 0$ be the annual interest rate that the decision maker uses for time discounting. The variable $t$ represents the number of weeks in the future that the subject would receive the payment if the given problem was randomly selected for payment.

Therefore, the utility of a lottery, $\ell=\left[\left(x_{1}, x_{2}\right) ;\left(p_{1}, p_{2}\right) ; t\right]$, such that it pays at time $t, x_{1}$ with probability $p_{1}$, and $x_{2}$ with probability $p_{2}$ where $p_{1}+p_{2}=1$ and $x_{1} \geq x_{2}$ is

$$
U(\ell)=e^{-r \cdot t / 52}\left(w\left(p_{1}\right) x_{1}^{1-\rho}+\left(1-w\left(p_{1}\right)\right) x_{2}^{1-\rho}-1\right) /(1-\rho)
$$

In order to estimate the parameters of the model, first we model the comparison between two lotteries $\ell_{a}$ and $\ell_{b}$ as follows: Let $\Delta_{a b}:=U\left(\ell_{a}\right)-U\left(\ell_{b}\right)$ be an index function. Using a distribution function $F\left(\Delta_{a b}\right)$, this index function is linked to the observed choices. This function maps any real number to a number in the interval $[0,1]$. The probability that the decision maker chooses a lottery $\ell_{a}$ over $\ell_{b}$ is given by $\operatorname{Pr}\left(\ell_{a}, \ell_{b}\right)=F\left(\Delta_{a b}\right)$. Luce (1959) shows that if we choose $F(\cdot)$ as the logistic CDF where $\lambda$ is the inverse standard deviation parameter, then the probability that the decision maker $i$ chooses a lottery $\ell_{a}$ over $\ell_{b}$ for question $j$ is equal to the binary logit such that:

$$
\operatorname{Pr}^{i j}\left(l_{a}, l_{b}\right)=\frac{e^{\lambda U\left(l_{a}\right)}}{e^{\lambda U\left(l_{a}\right)}+e^{\lambda U\left(l_{b}\right)}}
$$

\footnotetext{
${ }^{18}$ Following the literature, we call $\rho$ the risk parameter, although, as previously noted, the risk preferences of a decision maker with non-linear probability weighting function cannot be measured solely by $\rho$.

${ }^{19}$ Recently, Hsu, Krajbich, Zhao, and Camerer (2009) have provided neuroeconomic evidence that subjects have a non-linear probability weighting function, and that the one parameter functional form suggested by Prelec (1998) fits the data quite well. See also Footnote 7.
} 
where $\lambda$ can be interpreted as a rationality parameter. When $\lambda=0, \operatorname{Pr}\left(l_{a}, l_{b}\right)=0.5$, implying that the decision maker disregards the utilities of the lotteries and picks one of the two choices at random. On the other hand, as $\lambda \rightarrow \infty$, the decision maker chooses the lottery that gives a higher utility. The higher $\lambda$, it is more likely that the decision maker will pick the lottery with a higher utility (see Harrison and Rutström (2008) for a summary of models of choice with error).

Finally, we can then write the likelihood function as:

$$
L(\rho, r, \alpha, \lambda)=\prod_{i=1}^{N} \prod_{j=1}^{100} \operatorname{Pr}^{i j}\left(l_{a}, l_{b}\right)^{\mathbf{1}_{\left[c_{i j}=l_{a}\right]}}\left(1-\operatorname{Pr}^{i j}\left(l_{a}, l_{b}\right)\right)^{\mathbf{1}_{\left[c_{i j}=l_{b}\right]}}
$$

where $c_{i j} \in\left\{l_{a}, l_{b}\right\}$ is the choice of the decision maker $i$ for question $j$, and $\mathbf{1}_{[\cdot]}$ is the indicator function equal to 1 if the condition in [.] is satisfied, 0 otherwise.

\subsection{Estimation Results}

\subsubsection{Pooled Estimates}

We begin by reporting results pooling over our entire sample of subjects. Table 6 reports the maximum likelihood estimates of (1). ${ }^{20}$ In column (1), we assume that there is a single rationality parameter, $\lambda$, while in column (2), we allow for three possible rationality parameters: one for those problems $(\mathrm{a})$ and $(\mathrm{d})$ where all outcomes were certain $\left(\lambda_{\text {time }}\right)$; one for the problems (b), (c), (e), (f) and (g) where Option B was uncertain $\left(\lambda_{\mathrm{PLS}}\right)$; and one for the risk decision problems $(\mathrm{h}),(\mathrm{i})$ and $(\mathrm{j})\left(\lambda_{\text {risk }}\right)$. However, as can be seen from the estimates, the rationality parameters are quite similar, and a likelihood ratio test cannot reject that the $\lambda \mathrm{s}$ are, in fact, the same at the $5 \%$ level $(L R(2)=5.38 ; p=0.068)$.

As reported in Table 6, the implicit annual interest rate used by subjects is over $80 \%$ and the coefficient of relative risk aversion is 0.514, suggesting substantial impatience and risk aversion. However, since our empirical model explicitly allows for non-linear probability weighting, which we find to be highly significant, subjects are less risk averse than suggested by the estimate of $\rho$. Additionally, note that because we allow for non-linear probability weighting, our estimates of risk and time preferences are not directly comparable to the literature (e.g., Andersen et al. (2008), Andreoni and Sprenger (2012)). In Appendix C.2 we analyze some restricted models which facilitate comparison with the literature.

\footnotetext{
${ }^{20}$ We include all data, even those subjects who were dropped in the reduced form switch point analysis because of multiple switch points. Since the empirical model here assumes that subjects may make stochastic errors, we feel that it is inappropriate to drop these subjects (who may have been making errors) from the analysis. Whether or not they are included in the estimation, the results are qualitatively similar.
} 
Table 6: Estimation Results

\begin{tabular}{lcc}
\hline Parameter & $(1)$ & $(2)$ \\
\hline$\rho$ & 0.514 & 0.497 \\
& {$[0.439,0.579]$} & {$[0.416,0.567]$} \\
$r$ & 0.834 & 0.856 \\
& {$[0.299,1.301]$} & {$[0.336,1.325]$} \\
$\alpha$ & 0.752 & 0.768 \\
& {$[0.695,0.806]$} & {$[0.718,0.826]$} \\
$\lambda$ & 1.641 \\
& {$[1.251,2.135]$} & \\
$\lambda_{\text {time }}$ & \multicolumn{2}{c}{1.470} \\
& \multicolumn{2}{c}{$[1.100,2.016]$} \\
$\lambda_{\text {PLS }}$ & \multicolumn{2}{c}{1.651} \\
& \multicolumn{2}{c}{$1.215,2.201]$} \\
$\lambda_{\text {risk }}$ & & {$[1.102,1.998]$} \\
\hline obs & & 9600 \\
LL & -4717.78 & -4715.09 \\
\hline
\end{tabular}

* Confidence intervals were obtained via a bootstrap procedure. In each of 400 iterations, we drew a random sample of subjects, with replacement, and then estimated the model's parameters. We then take the 2.5 and 97.5 percentiles from the distribution of estimates as our confidence interval. Note that we draw our random sample at the level of the subject, taking each selected subject's 100 observations.

As can be seen from Table 6, we estimate $\alpha$, the probability weighting parameter, to be 0.752 . The upper bound of the $95 \%$ confidence interval of our estimate is only 0.806 , indicating that subjects have substantial non-linear probability weighting which is consistent with the literature (e.g. Jullien and Salanié (2000), Wu and Gonzalez (1996), Stott (2006), Snowberg and Wolfers (2010)). ${ }^{21}$ To facilitate interpretation of this parameter, note that $\alpha=0.752$ implies that a decision maker acts as though he perceives a 10 percent probability as being 15.4 percent and a 1 percent probability as being 4.3 percent. ${ }^{22}$ The net result is that subjects will appear significantly less risk averse for gambles involving small probabilities than would be suggested by the estimated risk parameter, $\rho$, by itself.

\subsubsection{Structural Results Demographic Categories}

We now show how estimates of the structural parameters vary along the three dimensions explored above: (a) self-reported lottery players vs. self-reported lottery abstainers; (b) male vs. female; and (c) those with a combined balance in their savings and checking accounts

\footnotetext{
${ }^{21}$ It also implies that such decision makers will engage in seemingly risk-seeking behavior for gambles involving low probabilities. For example, such a decision maker would prefer the lottery $[(510,10) ;(0.02,0.98)]$ to $\$ 20$ for sure.

${ }^{22}$ To see this, plug in probability values 0.1 and 0.01 into the probability weighting function, $w(p)=$ $e^{-(-\ln p)^{\alpha}}$, with $\alpha=0.752$.
} 
of more or less than $\$ 1000$. The results are presented in Table 7 . The top row of the table shows estimates of the parameters for the reference group, male non-lottery players with less than $\$ 1,000$ in savings. For this reference group, we estimate $\alpha=0.760, \rho=0.480$ and $r=1.328$. The model restricts the rationality parameters to be the same for all individuals, but allows for different rationality parameters for the different problem types.

Table 7: Structural Estimation Results Based on Observable Characteristics

\begin{tabular}{|c|c|c|c|c|c|c|}
\hline Parameter & $\lambda_{\text {time }}$ & $\lambda_{\text {PLS }}$ & $\lambda_{\text {risk }}$ & $\alpha$ & $\rho$ & $r$ \\
\hline constant & $1.591^{* * *}$ & $1.718^{* * *}$ & $1.452^{* * *}$ & $0.760^{* * *}$ & $0.480^{* * *}$ & $1.328^{* * *}$ \\
\hline female & & & & $0.059^{* * *}$ & 0.029 & -0.109 \\
\hline lottery & & & & $-0.038^{* *}$ & -0.005 & $0.440^{* * *}$ \\
\hline savings $>\$ 1000$ & & & & 0.012 & 0.013 & $-1.018^{* * *}$ \\
\hline & & & -4619.95 & $\mathrm{~N}$ & & $\overline{9600}$ \\
\hline
\end{tabular}

The subsequent rows of the table present estimates of how $\alpha, \rho$ and $r$ vary with gender, lottery play and savings amount. We find no significant difference in risk aversion or discount rates between men and women. However, we estimate that the probability weighting parameter $\alpha$ is 0.059 higher for women than for men. This difference is statistically significant at the 1-percent level, and implies that men overweight small probabilities more than women. This difference in probability weighting by men and women is consistent with the finding that men had stronger relative preferences for PLS than women. It suggests that the reason why men responded more strongly than women to PLS may be that they overweight the chance of winning a large prize when the probability of winning is small.

The next row shows how the estimated structural parameters varied between self-reported lottery players and non-players. We estimate that $\alpha$ for lottery players is 0.038 smaller than for non-players. This difference is statistically significant at the 5-percent level and implies that lottery players overweight small probabilities more than non-players. Interestingly, and perhaps surprisingly, we find no difference in risk-aversion between lottery players and nonplayers. We also find that lottery players are more impatient than non-players. The degree of impatience is unlikely to explain preferences for PLS relative to standard interest savings accounts, since both PLS and standard interest accounts pay interest equally far in the future. With this in mind, the structural estimates appear to suggest that lottery players have strong preferences for PLS because of their propensity to overweight small probabilities.

The final row of Table 7 shows estimates of how the structural parameters vary for subjects with more than $\$ 1,000$ in combined savings, relative to those with less. We find no difference in probability weighting or risk aversion between these two groups. Not surprisingly, we find that those with larger account balances are more future oriented. 


\section{$5 \quad$ Policy Experiments}

\subsection{Theoretical Background}

In this section we first show theoretically that if subjects have non-linear probability weighting, then introducing a PLS device will increase savings. We then conduct simulation exercises using the structural parameter estimates presented above to examine the conditions under which PLS products are more desirable than a traditional interest bearing asset. Throughout we assume that the decision maker chooses the alternative with higher utility. We begin by considering a situation in which the decision maker has $\$ \pi$ and can choose one of two options: (i) invest in a savings account that pays interest rate $i$ at time $t$ or (ii) invest in a PLS device that pays interest $I>i$ at time $t$ with probability $p$ and pays no interest with probability $1-p$. In order to keep things simple, we will assume that the expected cost to the bank is the same under both scenarios; that is, $I=i / p$, which means that larger prizes come with correspondingly small chances of winning them. ${ }^{23}$

Then the utility of saving in the interest option is

$$
U^{\text {int }}=e^{-r t} \frac{[(1+i) \pi]^{1-\rho}-1}{1-\rho},
$$

while the utility of saving in the PLS device is

$$
U^{\mathrm{pls}}=e^{-r t} \frac{w(p)[(1+i / p) \pi]^{1-\rho}+(1-w(p))[\pi]^{1-\rho}-1}{1-\rho} .
$$

Next, we show that one can design a prize-linked saving option such that the utility of the PLS option is higher than the utility of the sure interest paying option and both of them cost the same in expectation.

Proposition 1. For any $\alpha<1$ there exists a $p^{*} \in(0,1)$ such that for all $p<p^{*}, U^{p l s}>U^{i n t}$.

Proof. See Appendix D.

Technically, the result above may require the combination of an extremely small probability of winning paired (by construction) with an extremely large prize. However, given the parameter estimates that we reported earlier, PLS dominates standard interest bearing accounts even for "reasonable" probabilities and prize sizes. For example, in Figure 1, we plot the ratio $U^{\text {pls }} / U^{\text {int }}$ using our pooled parameter estimates from the last column of Table

\footnotetext{
${ }^{23}$ A similar analysis can be done by designing a PLS that makes the decision maker indifferent and the bank better off. As can be seen in the proof of Proposition 1, the main idea is to have non-linear probabilities for the decision maker.
} 
Figure 1: Ratio of $U^{\text {pls }} / U^{\text {int }}$ Using Pooled Estimates (4 Week Period)

(a) Low Interest Rates

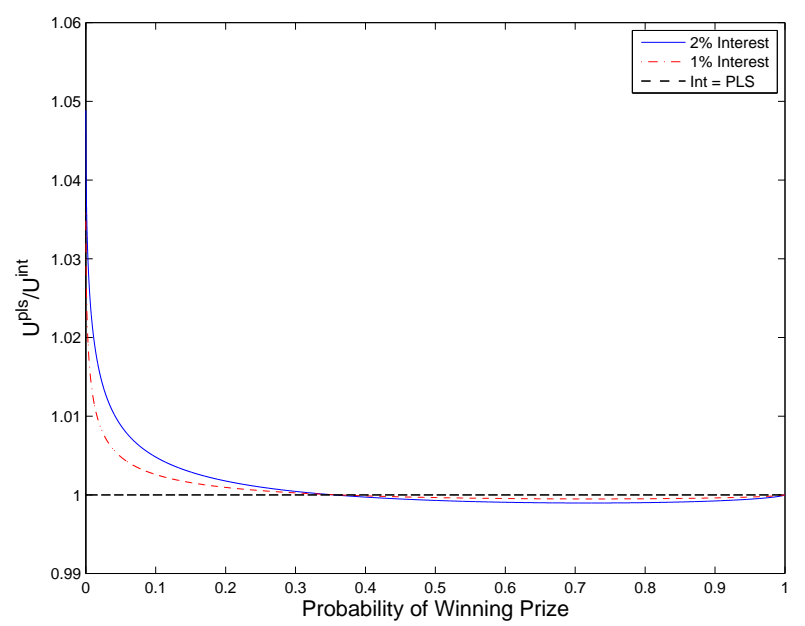

(b) High Interest Rates

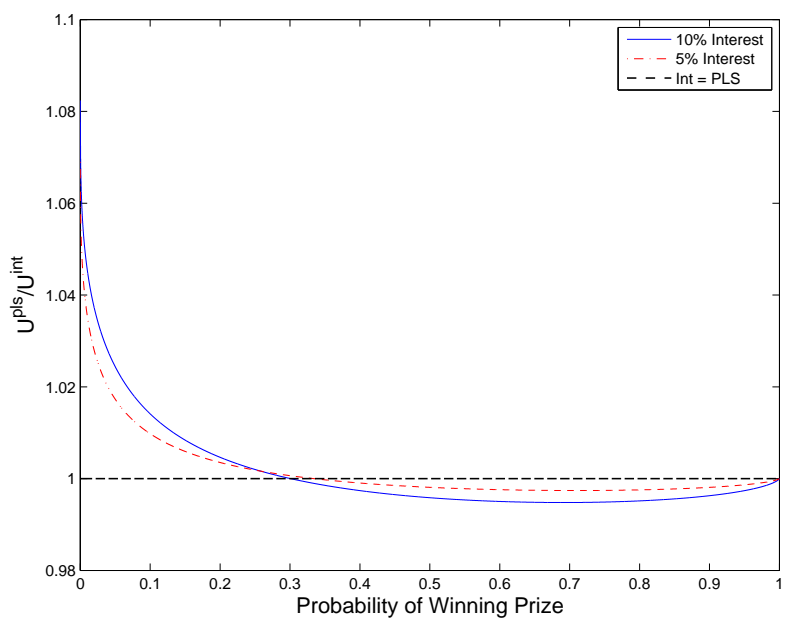

6 , and consider a decision maker who has $\$ 100$ to save over a four week period. Panel (a) considers interest rates of $i=1 \%$ and $i=2 \%$, and as can be seen, for probabilities of winning less than about 0.35 , the decision maker prefers the PLS savings device. On the other hand, in panel (b), which considers interest rates of $5 \%$ and $10 \%$, the decision maker prefers the PLS device for probabilities less than about $0.3 .^{24}$

Turn now to a situation in which a decision maker faces a portfolio choice problem. Specifically, she has $\$ \pi$ which can be allocated to current consumption, $x_{c}$, or future consumption, $x_{f}$. Additionally, assume that there are two types of investments: interest only and PLS. Specifically, if $x_{f, i}$ is invested in the interest only option, then in period $t$, the DM will receive $(1+i) x_{f, i}$. On the other hand, if $x_{f, p}$ is invested in the PLS device, then she will receive $(1+i / p) x_{f, p}$ with probability $p$ at time $t$ and $x_{f, p}$ with probability $1-p$, also at time $t$. The decision maker's problem is then to choose $\left\{x_{c}, x_{f, i}, x_{f, p}\right\}$ to maximize:

$$
\frac{x_{c}^{1-\rho}-1}{1-\rho}+e^{-r t} \frac{w(p)\left[x_{f, i}(1+i)+x_{f, p}(1+i / p)\right]^{1-\rho}+(1-w(p))\left[x_{f, i}(1+i)+x_{f, p}\right]^{1-\rho}-1}{1-\rho}
$$

subject to $x_{c}+x_{f, i}+x_{f, p}=\pi$.

\footnotetext{
${ }^{24}$ When the probability of winning the prize, $p$, changes in the horizontal axis, the prize of the corresponding PLS, $I$, changes to keep the expected return of PLS as same as the sure interest, i.e. $I=i / p$. For example, in Figure 1 (a), when interest rate, $i$, is $1 \%$ and probability of winning a prize, $p$, is $20 \%$, the corresponding PLS pays $I=0.01 / 0.2=5 \%$ interest with $20 \%$ chance.
} 
It is possible to show that, at the optimal solution, $x_{c} \in(0, \pi)$ and that:

$\left(x_{f, i}, x_{f, p}\right)= \begin{cases}\left(\frac{\pi}{\left[e^{-r t}(1+i)^{1-\rho}\right]^{-1 / \rho}+1}, 0\right), & \text { if }(A-1)(1+i)>0 \\ \left(0, \frac{\pi}{\left[e^{-r t}\left(w(p)(1+i / p)^{1-\rho}+1-w(p)\right)\right]^{-1 / \rho}+1}\right) & \text { if } A(1+i / p)<1 \&(A-1)(1+i)<0 \\ \left(x_{f, i}, x_{f, p}\right)>0, & \text { otherwise }\end{cases}$

where $A=\left(\frac{(1-w(p))}{w(p)(1 / p-1)}\right)^{1 / \rho}$.

Notice also that if the PLS option is not available, then the decision maker will always allocate $x_{f, i}^{I N T}=\frac{\pi}{\left[e^{-r t}(1+i)^{1-\rho}\right]^{-1 / \rho}+1}$ to future consumption.

Beyond this, we also have the following result:

Proposition 2. For all $\alpha \in(0,1)$ and all $\rho \in(0,1)$, there exists $\hat{p}<1$ such that for $p<\hat{p}$, the decision maker allocates all future consumption to the PLS device and that the amount of money devoted to future consumption, $x_{f, p}^{P L S}$ is larger than the amount devoted, $x_{f, i}^{I N T}$ when only interest-only savings are available.

Proof. See Appendix D.

That is, there is a probability of winning small enough (with prize accordingly large) such that a moderately risk averse decision maker (i.e., $\rho \in(0,1))$ who suffers from non-linear probability weighting (i.e., $\alpha \in(0,1))$ will allocate all future consumption to the PLS option and, moreover, this amount is larger than the amount she would allocate if she only had access to a standard interest-bearing account.

\section{$5.2 \quad$ Policy Experiment Results}

The descriptive results of Section 3 showed that subjects are more likely to choose the deferred option when it is a lottery than when it is a certain value. In Section 4 we rationalised such behavior by estimating subjects' probability weighting function, and found that subjects behave as if they have a non-linear probability weighting bias. We now ask whether decision makers, with the parameter estimates above, could be induced to increase their savings by making prize-linked savings devices available.

In Table 8 and Figure 2 we examine by how much money allocated to future consumption increases with the introduction of a PLS device (above and beyond a standard interest bearing account) which pays out a prize equal to $i / p$ with probability $p$. We report results for both pooled estimates and based on estimates from different (observable) sub-populations we identified in Section 3.3. The specific example in the table considers the percentage increase 
in money allocated to future consumption when PLS become available when the decision maker has $\$ 100$ to be allocated between current and future (in 4 weeks) consumption with $i=2 \%$ interest rate. ${ }^{25}$

Table 8: Estimates of the Percentage Increase in Money Allocated to Future Consumption When PLS is Offered

\begin{tabular}{|c|c|c|c|c|c|c|c|}
\hline \multirow[b]{2}{*}{$\operatorname{Pr}[$ Prize $]$} & \multirow[b]{2}{*}{ Pooled } & \multicolumn{2}{|c|}{ Gender } & \multicolumn{2}{|c|}{ Lottery } & \multicolumn{2}{|c|}{ Savings } \\
\hline & & Females & Males & Yes & $\mathrm{No}$ & $\leq \$ 1000$ & $>\$ 1000$ \\
\hline 0.0001 & 4.106 & 1.241 & 5.981 & 6.037 & 2.839 & 4.137 & 3.940 \\
\hline 0.0010 & 3.142 & 1.345 & 4.159 & 4.123 & 2.428 & 3.199 & 3.007 \\
\hline 0.0100 & 1.783 & 1.015 & 2.160 & 2.060 & 1.539 & 1.848 & 1.687 \\
\hline 0.0500 & 0.755 & 0.493 & 0.873 & 0.802 & 0.697 & 0.795 & 0.706 \\
\hline 0.1000 & 0.412 & 0.279 & 0.470 & 0.425 & 0.388 & 0.437 & 0.383 \\
\hline 0.2500 & 0.085 & 0.058 & 0.097 & 0.087 & 0.081 & 0.091 & 0.079 \\
\hline
\end{tabular}

As the table shows, the estimated structural parameters imply that individuals would reduce the amount of current consumption (i.e., save more) if presented with the option of PLS. Column 1 of Table 8 shows the estimated percentage increase in savings that would result from the offer of PLS for the pooled sample. Each row shows an estimate for a PLS account with a different size prize and different probability of winning; the expected returns to the accounts represented in each row are equal. The estimated parameters imply that PLS accounts with relatively high chances of winning and correspondingly smaller prizes would generate small increases in savings. PLS with larger prizes and smaller chances of winning would generate significantly more savings. For example, the estimates imply that a PLS with a $1 \%$ chance of winning would generate $1.8 \%$ more savings on average, and that a PLS account with a $0.1 \%$ chance of winning would generate more than $3 \%$ more savings than a standard interest account with the same expected return.

The table also shows that there is substantial heterogeneity in the estimated behavioral responses based on observable characteristics. For example, while the pooled estimates suggest savings will increase by $4 \%$ when the probability of receiving the prize is $0.01 \%$, the effect for males is nearly $6 \%$ while for females it is only 1.24\%. Similarly, lottery players increase savings by $6 \%$ while non-players only increase savings by $2.8 \%$. Contrary to our earlier results which hinted that people with lower savings would be more likely to increase savings when PLS is introduced, we only find a very small difference between those with high and those with low account balances.

\footnotetext{
${ }^{25}$ Note that the interest rate is paid at the end of the period and, therefore, is not an annual interest rate.
} 
Figure 2: Percentage Increase in Money Allocated to Future Consumption When PLS-based Savings Become Available
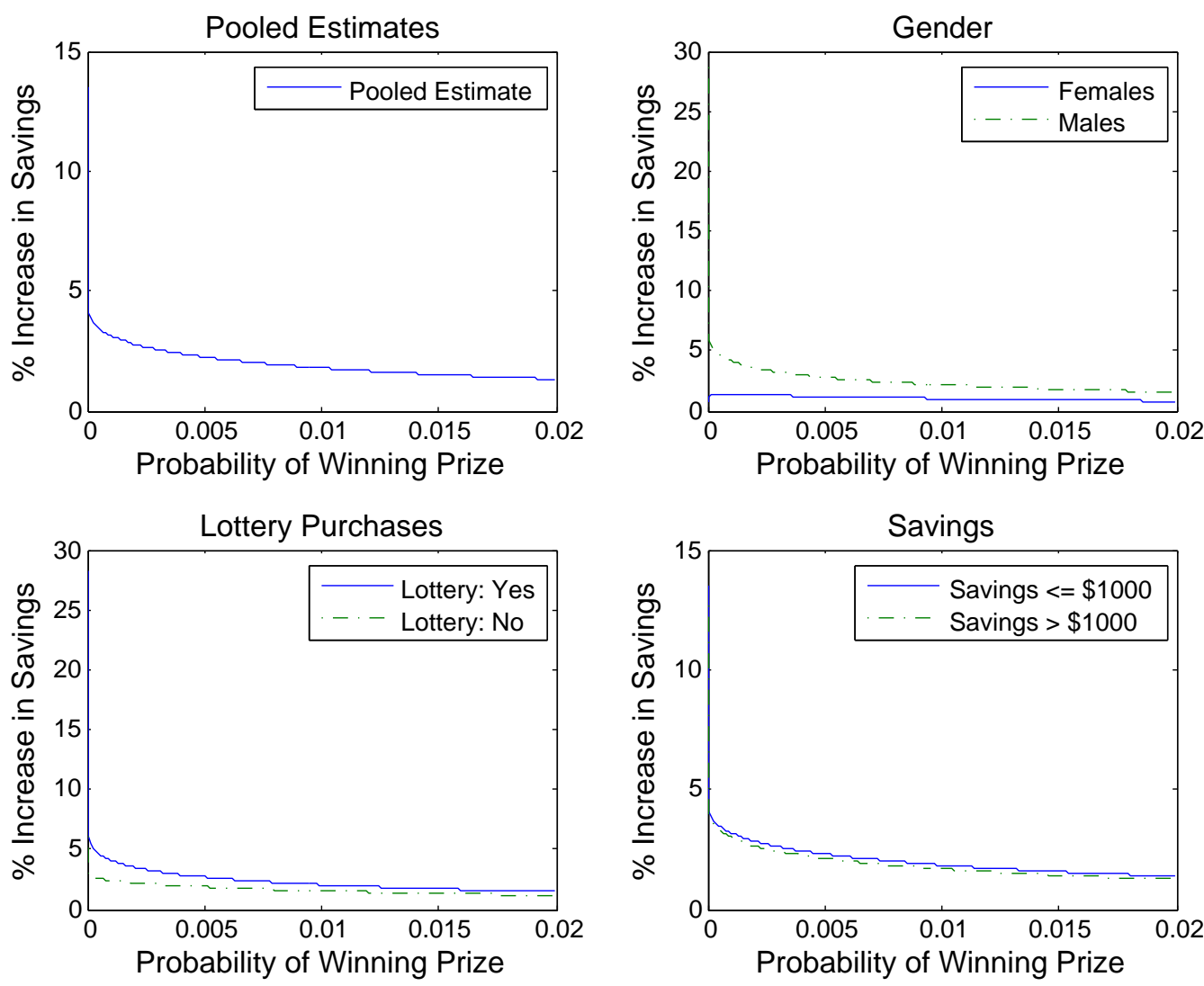

In this experiment, the consumer faces a timeframe of 4 weeks with a $2 \%$ interest rate and has $\$ 100$ to invest.

\section{Conclusion}

This paper has provided laboratory evidence on individual choices over earlier consumption versus later consumption (savings) as a function of whether the decision-maker is offered a standard interest bearing account or a prize-linked savings account. The data from the experiment demonstrate clearly that individuals are enticed to save at a higher rate - for a given expected return - if they are presented with a prize-linked savings choice. To the best of our knowledge, this is the first evidence showing that PLS products are more effective at inducing savings as compared to a standard interest bearing account offering the same expected return.

This finding should be of immediate interest to the research and policy community interested in innovations in the savings sphere. The existing evidence about PLS products coming from real world offerings of such products speaks only to the take-up of the product itself, and does not provide any guidance about whether the take-up of PLS reflects new 
savings or displaced savings from other potential assets. Establishing the effectiveness of PLS products at encouraging new savings in a laboratory setting is an important first step in providing insight into whether PLS products might encourage new saving, as opposed to displaced saving. We hope to have an opportunity to pursue follow up work in a field experiment setting. A subset of the authors of this article have been pursuing such opportunities for nearly a decade, but idiosyncratic implementation barriers have precluded that from taking place. Legal barriers to the offering of PLS products in the U.S. are becoming less binding, which hopefully will lead to fruitful opportunities to offer such products as part of a research demonstration. We leave it as an open question for future research whether PLS are substitutes or compliments to state lotteries. In some applications, PLS has been withdrawn from the market because it turned out to be substitute for state lotteries (South Africa) but they coexist with lotteries in many countries.

The paper has further provided structural estimates of the underlying decision parameters of interest. Using recent techniques, we jointly elicited parameters governing time preference, risk preference, and probability weighting. Not surprisingly, we find that probability weighting is related to the appeal of PLS products. This raises interesting questions about social welfare. Should we promote products in which the appeal is generated by misrepresentations of probabilities in the decision-maker's optimization problem? It also raises questions about long term effectiveness - in a repeated context, will consumers eventually adjust their probability weights to remove such "bias" from their decision making? The paper does not propose to answer these interesting questions. An additional limitation of the paper is that the experiment was not designed to isolate various explanations for the appeal of PLS. An additional possibility which we do not consider in this paper is non-stationary discount factors, as in Ahlbrecht and Weber (1997) and Stevenson (1992). An additional possibility is that it is simply fun. This raises the possibility that PLS products hold appeal for their entertainment value, something which others have considered in the context of gambling (c.f. Conlisk (1993)). Although given our data, it is possible to compare different structural models, we believe distinguishing among these explanations in a model free way is a fruitful task for future research.

\section{References}

Abdellaoui, M. (2000). Parameter-free elicitation of utilities and probability weighting functions. Management Science 47(11), 1497-1512.

Ahlbrecht, M. and M. Weber (1997). Preference for gradual resolution of uncertainty. Theory 
and Decision 43, 167-185.

Andersen, S., G. W. Harrison, M. I. Lau, and E. E. Rutström (2008). Eliciting risk and time preferences. Econometrica 76(3), 583-618.

Andreoni, J. and C. Sprenger (2012). Estimating time preferences from convex budget sets. American Economic Review 107(7), 3333-3356.

Azriele, Y., C. P. Chambers, and P. J. Healy (2012). Incentives in experiments: A theoretical analysis. Working Paper.

Barberis, N. and M. Huang (2008). Stocks as lotteries: The implications of probability weighting for security prices. American Economic Review 98(5), 2066-2100.

Barseghyan, L., F. Molinari, T. O'Donoghue, and J. C. Teitelbaum (Forthcoming). The nature of risk preferences: Evidence from insurance choices. American Economic Review.

Booij, A. S., B. M. S. van Praag, and G. van de Kuilen (2010). A parametric analysis of prospect theory's functionals for the general population. Theory and Decision 68(1-2), $115-148$.

Bruhin, A., H. Fehr-Duda, and T. Epper (2010). Risk and rationality: Uncovering heterogeneity in probability distortion. Econometrica 78(4), 1375-1412.

Chetty, R., J. Friedman, S. Leth-Petersen, T. Nielsen, and T. Olsen (2012). Active vs. passive decisions and crowd-out in retirement savings accounts: Evidence from denmark. NBER Working Paper 18565.

Conlisk, J. (1993). The utility of gambling. Journal of Risk and Uncertainty 6(3), 255-275.

Croson, R. and U. Gneezy (2009). Gender differences in preferences. Journal of Economic Literature 47(2), 1-27.

Cubitt, R., C. Starmer, and R. Sugden (1998). On the validity of the random lottery incentive scheme. Experimental Economics 1(2), 115-131.

Fehr-Duda, H., M. de Gennaro, and R. Schubert (2006). Gender, financial risk and probability weights. Theory and Decision 60(2-3), 283-313.

Fischbacher, U. (2007, June). z-tree: Zurich toolbox for ready-made economic experiments. Experimental Economics 10(2), 171-178. 
Gonzalez, R. and G. Wu (1999). On the shape of the probability weighting function. Cognitive Psychology 38(1), 129-166.

Guryan, J. and M. Kearney (2008). Gambling at lucky stores: Evidence from state lottery sales. American Economic Review 98(1), 458-473.

Harrison, G. W. and E. E. Rutström (2008). Risk aversion in the laboratory. In J. C. Cox and G. W. Harrison (Eds.), Risk Aversion in Experiments, Research in Experimental Economics, Volume 12. Bingley, U.K.: Emerald.

Holt, C. A. and S. K. Laury (2002). Risk aversion and incentive effects. American Economic Review 92(5), 1644-1655.

Hsu, M., I. Krajbich, C. Zhao, and C. F. Camerer (2009). Neural response to reward anticipation under risk is nonlinear in probabilities. Journal of Neuroscience 29(7), 23312337.

Hu, W.-Y. and J. S. Scott (2007). Behavioral obstacles in the annuity market. Financial Analsysts Journal 63(6), 71-82.

Jullien, B. and B. Salanié (2000). The case of racetrack bettors. Journal of Political Economy $108(3), 503-530$.

Kearney, M. (2005). State lotteries and consumer behavior. Journal of Public Economics 89, 2269-2299.

Kearney, M., P. Tufano, J. Guryan, and E. Hurst (2010). Making savers winners: An overview of prize-linked savings products. NBER Working Paper 16433.

Lichtenstein, S., P. Slovic, B. Fischhoff, M. Layman, and B. Combs (1978). Judged frequency of lethal events. Journal of Experimental Psychology: Human Learning and Memory 4(6), $551-578$.

Luce, R. D. (1959). Individual Choice Behavior: A Theoretical Analysis. New York: Wiley.

Madrian, B. and D. F. Shea (2001). The power of suggestion: Inertia in 401(k) participation and savings behavior. Quarterly Journal of Economics 116(4), 1149-1187.

Prelec, D. (1998). The probability weighting function. Econometrica 66(3), 497-527.

Snowberg, E. and J. Wolfers (2010). Explaining the favorite-long shot bias: Is it risk-love or misperceptions? Journal of Political Economy 118(4), 723-746. 
Starmer, C. (2000). Developments in non-expected utility theory: The hunt for a descriptive theory of choice under risk. Journal of Economic Literature 38(2), 332-382.

Stevenson, M. K. (1992). The impact of temporal context and risk on the judged value of future outcomes. Organizational Behavior and Human Decision Processes 52(3), 455-491.

Stott, H. (2006). Cumulative prospect theory's functaional menagerie. Journal of Risk and Uncertainty 32(2), 101-130.

Sydnor, J. (2010). (over)insuring modest risks. American Economic Journal: Applied Economics 2(4), 177-199.

Thaler, R. and S. Benartzi (2004). Save more tomorrow: Using behavioral economics to increase employee saving. Journal of Political Economy 112(1), S164-187.

Thaler, R. H. and C. R. Sunstein (2008). Nudge: Improving Decisions About Health, Wealth, and Happiness. Yale University Press.

Tversky, A. and D. Kahneman (1992). Advances in prospect theory: Cumulative representation of uncertainty. Journal of Risk and Uncertainty 5, 297-323.

Volpp, K. G., L. K. John, A. B. Troxel, L. Norton, J. Fassbender, and G. Loewenstein (2008a). Financial incentive-based approaches for weight loss financial incentive-based approaches for weight loss: A randomized trial. Journal of the American Medical Association 300(22), 2631-2637.

Volpp, K. G., L. K. John, A. B. Troxel, L. Norton, J. Fassbender, and G. Loewenstein (2008b). A test of financial incentives to improve warfarin adherence. BMC Health Services Research 8(272).

Wu, G. and R. Gonzalez (1996). Curvature of the probability weighting function. Management Science 42(12), 1676-1690.

Yaari, M. E. (1987). The dual theory of choice under risk. Econometrica 55(1), 95-115.

\section{A Instructions}

Welcome and thank you for coming to participate in todayï $; \frac{1}{2} \mathrm{~s}$ experiment. This experiment is funded by the University of Maryland.

This is a two-part study. In the first part, you will face 10 sets of decision questions, which will take less than 1 hour. In the second part, you need to fill out a questionnaire, which will take 
about 15 minutes. Today, you will receive $\$ 7$ for showing-up on time and $\$ 3$ for completing the questionnaire at the end of the experiment. Additionally, you may earn a substantial amount of money in the first part of the experiment. You are required to come back to the lab again to receive those additional earnings.

During the experiment it is important not to talk to any other subjects, surf the web or use your cell phones. So please turn your cell phones off and remember if you have any questions, just raise your hand and we will come by to answer them.

\section{PART I:}

In this experiment, you will face 10 sets of decision questions. On each set of decision questions, you will be asked to make 10 decisions. Each decision is a paired choice between "Option A" and "Option B". Therefore, in total, you will make 100 decisions today.

All of the decisions you must make have the same general form. You are choosing between "Option A" and "Option B". Each option is either a lottery with two possible outcomes or a sure payment. Each option also specifies the date that it will be paid.

An example of the screen you will see for a set of decision questions is given in Figure 3. Note that you are asked to make 10 decisions on this screen. As you can see, for each decision, you must choose between Option A and Option B. You may choose Option A for some decisions and Option B for others, and you may change your decisions and make them in any order. Once you have made all of your decisions, press the Submit button and you will be taken to the next, if any decision problem. Note that after you have pressed the submit button, you will no longer be able to change your decisions.

In this example, Option A pays in two weeks, and Option B pays in six weeks. Note that in all the questions, Option A pays $\$ 15$ for sure; Option B is a lottery that pays either $\$ 25$ or $\$ 15$. In Question 1, Option B pays $\$ 25$ with probability 0.1 and pays $\$ 15$ with probability 0.9 . In Question 2 , Option B pays $\$ 25$ with probability 0.2 and pays $\$ 15$ with probability 0.8 , etc. In Question 10 , Option B pays $\$ 25$ with probability 1 (i.e. $\$ 25$ for sure).

\section{Notes:}

1. Your payment will be based on one of the 100 decisions that will be randomly selected. Here is a ten-sided die that will be used to determine payoffs; the faces are numbered 0 to 9. After you have made all of your choices, and you have completed the questionnaire, the experimenter will come and let you throw the die twice. The first time you roll the die, will determine which of the 10 sets of decision questions will be used in determining your payoff. The second time you roll the die, will determine which of the decisions will be used to determine your payoff. For example, if you roll a 7 and then a 3, then this means that the 3rd decision on the 7th set of decision questions will be used to determine your payoff. 
Figure 3: Experimental Interface: Sample Screen

\begin{tabular}{|c|c|c|c|c|c|c|c|c|c|}
\hline & \multicolumn{9}{|c|}{$\begin{array}{l}\text { Set } 3 \text { of } 10 . \\
\text { Below you wall find } 10 \text { questions. For each question you are asked to state whether you would prefer to have the bundie } \\
\text { described in Option A or Option B Noto that any payments mado for Option A wall bo paid in } 2 \text { weeks. Whilo any poyments for } \\
\text { Option B wall be paid in } 6 \text { weeks. }\end{array}$} \\
\hline \multirow[b]{3}{*}{ 1) } & \multicolumn{3}{|c|}{$\begin{array}{c}\text { Option A } \\
\text { Pays in } 2 \text { woeks. April 11, } 2012\end{array}$} & \multirow{2}{*}{$\begin{array}{l}\text { I proter } \\
\text { Option A }\end{array}$} & \multirow{2}{*}{$\begin{array}{l}\text { I prefer } \\
\text { Option B }\end{array}$} & \multicolumn{4}{|c|}{$\begin{array}{c}\text { Option B } \\
\text { Pays in } 6 \text { woeks - May 9, 2012 }\end{array}$} \\
\hline & Prob. & uso & Prod. UsD & & & Prob & USD & Prob. & uso \\
\hline & 1 & 315 & & $r$ & r & 0.1 & 525 & 0.9 & \$15 \\
\hline 2) & 1 & 515 & & $r$ & $r$ & 0.2 & 525 & 0.8 & s 15 \\
\hline 3) & 1 & 315 & & $r$ & $r$ & 0.3 & 525 & 07 & 515 \\
\hline 4) & 1 & S is & & $r$ & $r$ & 0.4 & 525 & 0.6 & S 15 \\
\hline 5) & ' & 515 & & $r$ & $r$ & OS & $\$ 25$ & o. & s 15 \\
\hline ๑) & 1 & $\$ 15$ & & $r$ & $r$ & 0.6 & $\$ 25$ & 0.4 & 515 \\
\hline$n$ & 1 & 515 & & $r$ & $r$ & or & 525 & 0.3 & S 15 \\
\hline 8) & 1 & S 15 & & $r$ & $r$ & 0.8 & $\$ 25$ & 0.2 & \$ 15 \\
\hline 9) & , & S 15 & & $r$ & $r$ & 09 & $\$ 25$ & a. & S 15 \\
\hline 100 & , & 515 & & $r$ & r & 10 & 525 & 0.0 & S 15 \\
\hline & & & & & & & & & \\
\hline
\end{tabular}

If you roll 0, it will correspond to 10 . Since each decision is equally likely to be selected, you should pay equal attention to each question.

2. Depending on your choice, there are two possibilities:

(a) If the Option you chose in the randomly determined decision question is paying an amount for sure, then you will receive that amount at the specified date for that option.

(b) If the Option you chose in the randomly determined decision question is a lottery, you will roll the die to determine the outcome of the lottery.

For example, suppose that that Option pays $\$ 25$ with probability 0.1 and $\$ 21$ with probability 0.9 in two weeks. In this case, you will roll the ten-sided die one more time. If a 1 comes up, then you will receive $\$ 25$ in two weeks, while if a $2,3,4,5,6,7,8,9$, or 0 comes up, then you will receive $\$ 21$ in two weeks.

As a further example, suppose that that Option pays $\$ 215$ with probability 0.035 and $\$ 15$ with probability 0.965 in five weeks. In this case, you will roll the die three times. These three rolls will correspond to a number from 000 to 999. For example:

- If you roll a 4, a 6 and an 8 (in that order), then the number corresponds to 468.

- If you roll 0 three times, then this corresponds to the number 000.

- If you roll a 7, a 0 and a 2 (in that order), then the number corresponds to 702. 
In this example, if the corresponding number you roll is $001,002, \ldots$, or 035 , then you will receive $\$ 215$ in five weeks. If you roll $036,037, \ldots, 999$, or 000 , then you will receive $\$ 15$ in five weeks.

3. The date at which you will be paid for Option A may be different than the date at which you will be paid for Option B. For all problems Option B will pay either at the same time or strictly later than Option A.

4. For all decision questions, the date at which you will be paid is in the future. Once, the amount you will receive and the payment date are determined as explained above, you will be given an envelope to write your name, email address, the amount and the payment date. This information will be seen only by Professor Ozbay, Director of the Experimental Economics Laboratory at the UMD, and his assistants. Your identity will not be a part of the data analysis and any identifying information will be destroyed after the payment. You will be assigned a participant number, and only the participant number will remain in the data set.

5. When you come to the lab on the specified date anytime from 9:00am to 5:00pm, one of Professor Ozbay's assistants will be here to give your envelope with your specified amount. As a reminder to you, the day before you are scheduled to receive your payment, we will send you an e-mail notifying you the payment date. You may find Professor Ozbay's business card on your desk. If there is any problem regarding your payment, you should immediately contact Professor Ozbay.

\section{Part II:}

Once you have finished all ten sets of decision questions, you will be asked to fill a questionnaire.

If you have any questions, please raise your hand now, otherwise we will begin with the experiment.

\section{B Survey Questions}

1. Age:

2. Gender:

3. Academic major:

4. Do you work in paid employment?

5. Do you have a checking account?

6. At the end of last month (after you paid all your monthly bills and did all your monthly spending), about how much money remained in your checking accounts? 
7. Do you have a separate savings account that differs from your checking account?

8. At the end of last month (after you paid all your monthly bills and did all your monthly spending), about how much money was in your savings accounts?

9. Do you have any credit cards?

10. At the end of last month (after you made your monthly payments to your credit card companies), what was the total remaining outstanding balances on all of your credit cards?

11. What is the average annual savings account interest rate in the United States?

12. Suppose you had $\$ 100$ in a savings account and the interest rate was $2 \%$ per year. After 5 years, how much do you think you would have in the account if you left the money to grow?
(a) More than $\$ 102$
(b) Exactly $\$ 102$
(c) Less than $\$ 102$
(d) Do not know
(e) Refuse to answer

13. Imagine that the interest rate on your savings account was $1 \%$ per year and inflation was $2 \%$ per year. After 1 year, how much would you be able to buy with the money in this account?
(a) More than today
(b) Exactly the same
(c) Less than today
(d) Do not know
(e) Refuse to answer

14. A fair coin will be flipped 3 times. What is the probability that the coin will land on tails exactly once?
(a) $1 / 8$
(b) $1 / 3$
(c) $3 / 8$
(d) $5 / 8$ 
15. During the last twelve months, have you or anyone in your household ever bought lottery ticket for games like Lotto or Powerball, dailies like pick-4, or instant and scratch-off tickets? If answer to 15 is yes:

16. During the past twelve months, think about how often you or someone in your household bought such lottery tickets? Choose one of the following:
(a) About every day
(b) One to three times a week
(c) Once or twice a month
(d) A few times all year
(e) Only once in the past year

If answer to 15 is yes:

17. What is your favorite lottery game? Choose one of the following:
(a) Large Multi-state lotteries like Mega Millions or Powerball
(b) Other big jackpot lotteries like Michigan Lotto
(c) Daily Games like Pick-3 or Pick-4
(d) Instant/Scratch-off Tickets
(e) No Favorite.

18. During the last twelve months, have you or anyone in your household ever gambled at a casino or in any other non-lottery outlet?

If answer to 18 is yes:

19. During the past twelve months, think about how often you or someone in your household bought such lottery tickets? Choose one of the following:
(a) About every day
(b) One to three times a week
(c) Once or twice a month
(d) A few times all year
(e) Only once in the past year 


\section{Supplemental Results}

\section{C.1 Heterogeneity in PLS}

Table C.1: Regression estimates of heterogeneous responses to PLS

\begin{tabular}{|c|c|c|c|c|}
\hline & \multicolumn{2}{|c|}{ Delay payment } & \multicolumn{2}{|c|}{ Switch point } \\
\hline & $(1)$ & $(2)$ & $(3)$ & $(4)$ \\
\hline PLS · Lottery player & $\begin{array}{c}0.103^{* *} \\
(0.043)\end{array}$ & $\begin{array}{c}0.105^{* *} \\
(0.041)\end{array}$ & $\begin{array}{c}-1.073^{* *} \\
(0.445)\end{array}$ & $\begin{array}{c}-1.089^{* *} \\
(0.415)\end{array}$ \\
\hline PLS · Female & $\begin{array}{r}-0.069^{*} \\
(0.041)\end{array}$ & $\begin{array}{r}-0.078^{*} \\
(0.041)\end{array}$ & $\begin{array}{c}0.801^{*} \\
(0.415)\end{array}$ & $\begin{array}{c}0.866^{* *} \\
(0.419)\end{array}$ \\
\hline PLS $\cdot$ Savings $>\$ 1000$ & & $\begin{array}{c}-0.075^{* *} \\
(0.036)\end{array}$ & & $\begin{array}{c}0.724^{*} \\
(0.369)\end{array}$ \\
\hline Lottery player & $\begin{array}{r}-0.103 \\
(0.062)\end{array}$ & $\begin{array}{r}-0.109^{*} \\
(0.058)\end{array}$ & $\begin{array}{c}1.140^{*} \\
(0.632)\end{array}$ & $\begin{array}{c}1.184^{* *} \\
(0.594)\end{array}$ \\
\hline Female & $\begin{array}{c}0.012 \\
(0.066)\end{array}$ & $\begin{array}{c}0.034 \\
(0.063)\end{array}$ & $\begin{array}{r}-0.330 \\
(0.689)\end{array}$ & $\begin{array}{r}-0.499 \\
(0.637)\end{array}$ \\
\hline Savings $>\$ 1000$ & & $\begin{array}{l}0.197^{* * *} \\
(0.056)\end{array}$ & & $\begin{array}{c}-1.888^{* * *} \\
(0.587)\end{array}$ \\
\hline PLS & $\begin{array}{c}0.072^{\text {*** }} \\
(0.025)\end{array}$ & $\begin{array}{l}0.111^{* * *} \\
(0.035)\end{array}$ & $\begin{array}{c}-0.704^{* * *} \\
(0.252)\end{array}$ & $\begin{array}{c}-1.083^{* * *} \\
(0.353)\end{array}$ \\
\hline Constant & $\begin{array}{c}0.752^{\text {*** }} \\
(0.051)\end{array}$ & $\begin{array}{l}0.650^{* * *} \\
(0.062)\end{array}$ & $\begin{array}{c}3.451^{\text {*** }} \\
(0.511)\end{array}$ & $\begin{array}{c}4.437^{* * *} \\
(0.631)\end{array}$ \\
\hline $\begin{array}{l}R^{2} \\
\mathrm{~N}\end{array}$ & $\begin{array}{r}0.018 \\
6720\end{array}$ & $\begin{array}{r}0.049 \\
6720\end{array}$ & $\begin{array}{c}0.031 \\
644\end{array}$ & $\begin{array}{c}0.080 \\
644\end{array}$ \\
\hline
\end{tabular}

Note: Each column presents the results from a regression in which the dependent variable is either an indicator for choosing option B ("Delay payment") or the switch point. In the delay payment regressions, each observation is a subject making a choice in a question in a problem; in the switch point regressions, each observation is a subject's switch point for a problem. The regressions in columns (2) and (4) include the following regressors: an indicator for being a PLS problem, an indicator for being a self-reported lottery player, an indicator for having greater than $\$ 1000$ in combined savings and checking account balances, and interactions between the PLS indicator and each of the three heterogeneity variables (lottery, female, savings). Standard errors are robust to heteroskedasticity and account for subject-level correlation in random errors. Asterisks indicate standard levels of statistical significance. ${ }^{* * *}: p<0.01,{ }^{* *}: p<0.05,{ }^{*}: p<0.10$. 


\section{C.2 Structural Estimation Results: Restricted Models}

Here we expand upon Table 6 from the main body of the text to further demonstrate the importance of jointly estimating risk, time and probability weighting parameters. Specifically, in Table C.2 we repeat the unrestricted model results but also consider two restricted models: linear probability weighting $(\alpha=1)$ and linear probability weighting and risk neutrality $(\alpha=1$ and $\rho=0)$. As can be seen, when we restrict $\alpha=1$, subjects appear substantially less risk averse and more patient. Furthermore, behavior appears much more random, with our estimates of $\lambda$ significantly lower. When we additionally impose $\rho=0$ (i.e., risk neutrality), we continue to observed biased estimates of time preferences, and a further decent into randomness, with our estimates of $\lambda$ closer yet to 0 .

Table C.2: Estimation Results: Unrestricted and Restricted Models

\begin{tabular}{|c|c|c|c|c|c|c|}
\hline \multirow{3}{*}{ Parameter } & \multicolumn{3}{|c|}{ One Rationality Parameter } & \multicolumn{3}{|c|}{ Separate Rational Parameters } \\
\hline & \multirow{2}{*}{ Full Model } & \multicolumn{2}{|c|}{ Restricted Models } & \multirow{2}{*}{ Full Model } & \multicolumn{2}{|c|}{ Restricted Models } \\
\hline & & $\alpha=1$ & $\rho=0 ; \alpha=1$ & & $\alpha=1$ & $\rho=0 ; \alpha=1$ \\
\hline \multirow[t]{2}{*}{$\rho$} & 0.514 & 0.155 & 0 & 0.497 & 0.164 & 0 \\
\hline & {$[0.44,0.58]$} & {$[0.09,0.22]$} & & {$[0.42,0.57]$} & {$[0.08,0.25]$} & \\
\hline \multirow[t]{2}{*}{$r$} & 0.834 & 0.03 & 0 & 0.856 & 0.579 & 0.798 \\
\hline & {$[0.30,1.30]$} & {$[0.00,0.97]$} & {$[0.00,0.64]$} & {$[0.34,1.33]$} & {$[0.00,1.33]$} & {$[0.00,1.85]$} \\
\hline \multirow[t]{2}{*}{$\alpha$} & 0.752 & 1 & 1 & 0.768 & 1 & 1 \\
\hline & {$[0.70,0.81]$} & & & {$[0.72,0.83]$} & & \\
\hline \multirow[t]{2}{*}{$\lambda$} & 1.641 & 0.426 & 0.227 & & & \\
\hline & {$[1.25,2.14]$} & {$[0.34,0.57]$} & {$[0.20,0.27]$} & & & \\
\hline \multirow[t]{2}{*}{$\lambda_{\text {time }}$} & & & & 1.47 & 0.442 & 0.283 \\
\hline & & & & {$[1.10,2.02]$} & {$[0.31,0.67]$} & {$[0.22,0.39]$} \\
\hline \multirow[t]{2}{*}{$\lambda_{\mathrm{PLS}}$} & & & & 1.651 & 0.617 & 0.342 \\
\hline & & & & {$[1.22,2.20]$} & {$[0.43,0.87]$} & {$[0.29,0.41]$} \\
\hline \multirow[t]{2}{*}{$\lambda_{\text {risk }}$} & & & & 1.482 & 0.381 & 0.169 \\
\hline & & & & {$[1.10,2.00]$} & {$[0.26,0.57]$} & {$[0.15,0.20]$} \\
\hline obs & 9600 & 9600 & 9600 & 9600 & 9600 & 9600 \\
\hline LL & -4717.78 & -4845.71 & -4954.29 & -4715.09 & -4802.66 & -4880.63 \\
\hline $\begin{array}{l}{ }^{*} \text { Confidence i } \\
\text { subjects, with } \\
\text { the distributio } \\
\text { taking each sel } \\
\text { restrict } \alpha=1 \\
\text { particular valu }\end{array}$ & $\begin{array}{l}\text { ervals were obt } \\
\text { placement, anc } \\
\text { of estimates as }\end{array}$ & led via a boo & $\begin{array}{l}\text { ap procedure. In } \\
\text { e model's parame } \\
\text { rval. Note that w }\end{array}$ & $\begin{array}{l}\text { ach of } 400 \text { iterat } \\
\text { rs. We then tak } \\
\text { draw our random } \\
\text { columns, we rep } \\
\text { s indicate that t }\end{array}$ & $\begin{array}{l}\text { ns, we drew a } \\
\text { he } 2.5 \text { and } 97 \\
\text { ample at the le }\end{array}$ & $\begin{array}{l}\text { andom sample of } \\
\text { percentiles from } \\
\text { el of the subject, } \\
\text { stimations which } \\
\text { restricted to the }\end{array}$ \\
\hline
\end{tabular}

\section{Omitted Proofs}

Proposition 1. For any $\alpha<1$ there exists a $p^{*} \in(0,1)$ such that for all $p<p^{*}, U^{p l s}>U^{i n t}$.

Proof. To prove this, it is enough to show that as $p$ goes to $0, U^{\text {PLS }} / U^{\text {INT }}$ goes to infinity. This is 
equivalent to show that $\lim _{p \rightarrow 0} w(p)(1+i / p)^{1-\rho}=\infty$.

$$
\begin{aligned}
\lim _{p \rightarrow 0} w(p)(1+i / p)^{1-\rho} & =\lim _{p \rightarrow 0} \frac{(1+i / p)^{1-\rho}}{e^{(-\ln p)^{\alpha}}} \\
& =\lim _{p \rightarrow 0}\left(\frac{1+i / p}{e^{\frac{(-\ln p)^{\alpha}}{1-\rho}}}\right)^{1-\rho} \\
& =\lim _{z \rightarrow \infty}\left[e^{-\frac{z^{\alpha}}{1-\rho}}+i e^{z-\frac{z^{\alpha}}{1-\rho}}\right]^{1-\rho} \\
& =\infty
\end{aligned}
$$

The first and second equalities rearrange the expression; the third equality comes from the change of variables $z=-\ln p$. The final equality comes from the fact that for $\alpha, \rho \in(0,1)$, $z-\frac{z^{\alpha}}{1-\rho} \rightarrow \infty$

Proposition 2. For all $\alpha \in(0,1)$ and all $\rho \in(0,1)$, there exists $\hat{p}<1$ such that for $p<\hat{p}$, the decision maker allocates all future consumption to the PLS device and that the amount of money devoted to future consumption, $x_{f, p}^{P L S}$ is larger than the amount devoted, $x_{f, i}^{I N T}$ when only interest-only savings are available.

Proof. We begin by showing that for $p$ small enough, the consumer places all savings in the PLS device. To show this, it is enough to show that $1-A(1+i / p)>0$ and $(A-1)(1+i)<0$ for $p$ sufficiently small. The proof will be complete if we can show that $\lim _{p \rightarrow 0} A=0$ and $\lim _{p t o 0} A / p=0$. Indeed, consider the first limit:

$$
\begin{aligned}
\lim _{p \rightarrow 0} A & =\lim _{p \rightarrow 0}\left(\frac{(1-w(p))}{w(p)(1 / p-1)}\right)^{1 / \rho} \\
& =\lim _{z \rightarrow \infty}\left(\frac{1-e^{-z^{\alpha}}}{e^{-z^{\alpha}}\left(e^{z}-1\right)}\right)^{1 / \rho} \\
& =\lim _{z \rightarrow \infty}\left(\frac{1}{e^{z-z^{\alpha}}-e^{-z^{\alpha}}}-\frac{1}{e^{z}-1}\right)^{1 / \rho} \\
& =0,
\end{aligned}
$$

where the second equality comes from the change of variables $p=e^{-z}$ and the final equality comes from the fact that $\alpha \in(0,1)$ so that $z-z^{\alpha} \rightarrow \infty$ as $z \rightarrow \infty$. 
Consider now the second limit:

$$
\begin{aligned}
\lim _{p \rightarrow 0} \frac{A}{p} & =\lim _{p \rightarrow 0} \frac{1}{p}\left(\frac{(1-w(p))}{w(p)(1 / p-1)}\right)^{1 / \rho} \\
& =\lim _{z \rightarrow \infty} e^{z}\left(\frac{1-e^{-z^{\alpha}}}{e^{-z^{\alpha}}\left(e^{z}-1\right)}\right)^{1 / \rho} \\
& =\lim _{z \rightarrow \infty}\left(\frac{e^{\rho z}-e^{\rho z-z^{\alpha}}}{e^{-z^{\alpha}}\left(e^{z}-1\right)}\right)^{1 / \rho} \\
& =\lim _{z \rightarrow \infty}\left(\frac{1}{e^{(1-\rho) z-z^{\alpha}}-e^{-\left(\rho z+z^{\alpha}\right)}}-\frac{1}{e^{(1-\rho) z}-e^{-\rho z}}\right)^{1 / \rho} \\
& =0,
\end{aligned}
$$

where again the second equality comes from the change of variables $p=e^{-z}$ and the final equality comes from the fact that $\rho, \alpha \in(0,1)$, so that $(1-\rho) z-z^{\alpha} \rightarrow \infty$ and $(1-\rho) z \rightarrow \infty$ as $z \rightarrow \infty$.

To prove the second part of the proposition - that the consumer will save more for future consumption with PLS than an interest-only device, we must show that:

$$
\frac{\pi}{\left[e^{-r t}\left(w(p)(1+i / p)^{1-\rho}+1-w(p)\right)\right]^{-1 / \rho}+1}>\frac{\pi}{\left[e^{-r t}(1+i)^{1-\rho}\right]^{-1 / \rho}+1}
$$

We can rewrite the above expression as:

$$
\left[e^{-r t}(1+i)^{1-\rho}\right]^{-1 / \rho}>\left[e^{-r t}\left(w(p)(1+i / p)^{1-\rho}+1-w(p)\right)\right]^{-1 / \rho}
$$

which can further be rewritten as:

$$
(1+i)^{1-\rho}<w(p)(1+i / p)^{1-\rho}+1-w(p)
$$

By Proposition 1, we know that this inequality will be satisfied for $p$ small enough. 